\title{
Aproximación al estudio de los niños expósitos en la Sevilla de finales del siglo XVI y primera mitad del XVII a través del análisis de los libros de bautismo
}

\author{
Baltasar Arias Pérez'; Silvia-María Pérez-González²
}

Recibido: 5 de julio de 2020 / Aceptado: 27 de abril de 2021

Resumen. Este artículo tiene como objetivo estudiar los niños expósitos de Sevilla a finales del siglo XVI y la primera mitad del XVII. En este sentido quiere ser una aportación al panorama de la beneficencia española en relación con los niños abandonados durante la Modernidad, panorama que, pese a que aún manifiesta ciertos desequilibrios, se ha visto enormemente enriquecido con nuevos estudios abordados desde perspectivas multidisciplinares. La base documental analizada está constituida por 5600 partidas aportadas por los libros de bautismos conservados en la parroquia de la Magdalena. Por ello sus principales objetivos son estudiar la situación de los expósitos en cuanto a las cifras anuales de niños abandonados, los porcentajes por sexo, la onomástica, los posibles vínculos familiares en el futuro por medio de la adopción, y también los espirituales a partir de las figuras de los padrinos, así como la respuesta de la Iglesia y la religiosidad a este fenómeno.

Palabras clave. Expósito; Edad Moderna; Sevilla; Partidas de bautismo; Familia; Historia de la Iglesia

[en] An approach to the study of foundlings in Seville at the end of the 16th century and the first half of the 17th century through the analysis of baptism books.

\begin{abstract}
This article aims to study the foundlings of Seville at the end of the 16th century and the first half of the 17th century. In this regard, it is intended to be a contribution to the panorama of Spanish charity in relation to abandoned children during the Early Modern Period, a panorama which, despite still manifesting certain imbalances, has been enormously enriched by new studies approached from multi-institutional perspectives. The documentary base on which it is based consists of 5,600 items contributed by the baptismal books kept in the parish of La Magdalena. Therefore, its main objectives are to study the situation of the foundlings in terms of annual figures of abandoned children, percentages by sex, names, family and spiritual ties based on the figures of the godparents, as well as the response of the Church and religion to this phenomenon.
\end{abstract}

Keywords. Foundling; Early Modern Period; Seville; Baptism certificates; Family; History of Church

1 Alumno colaborador del Área de Historia Medieval de la Universidad Pablo de Olavide

E-mail: baltasararias97@gmail.com

ORCID: https://orcid.org/0000-0002-0225-0682

2 Profesora Titular del Área de Historia Medieval de la Universidad Pablo de Olavide

E-mail: spergon@upo.es

ORCID: https://orcid.org/0000-0002-3535-1826 
Sumario: Introducción. Sevilla a finales del siglo XVI y la primera mitad del XVII. Análisis de los registros bautismales de los expósitos sevillanos. Consideraciones finales. Bibliografía.

Cómo citar: Arias Pérez, B.; Pérez-González, S.-M. (2021). Aproximación al estudio de los niños expósitos en la Sevilla de finales del siglo XVI y primera mitad del XVII a través del análisis de los libros de bautismo, en Cuadernos de Historia Moderna 46.1, 207-233.

\section{Introducción}

El presente trabajo tiene como finalidad analizar la situación de los niños expósitos de la parroquia de la Magdalena de Sevilla durante los siglos XVI y XVII, siendo nuestros principales objetivos estudiar la situación de los expósitos y la respuesta de la Iglesia y la religiosidad a este fenómeno. Se inserta dentro de una línea historiográfica cuyo objeto de análisis, los niños abandonados, ha sido abordado desde múltiples disciplinas que no se limitan a las más directamente implicadas como la demografía, la sociología o la estadística. En este sentido, como ha expuesto García Jiménez ${ }^{3}$, la exposición de niños es un fenómeno que responde a múltiples variables. No sólo podemos hablar de problemas económicos como la falta de recursos o la pobreza ocasionada por las crisis económicas, sino que tras esta triste realidad se enconden numerosas razones de índole mental, moral o de comportamiento público, como el rechazo social a los hijos nacidos fuera del matrimonio ${ }^{4}$, con la consiguiente carga de prejuicios y consideración de inferioridad ${ }^{5}$.

Fue a partir del reinado de los Reyes Católicos, al socaire de una renovación de la consideración social del niño por parte de autores como Vives o Tomás Moro ${ }^{6}$, cuando los marginados, entre ellos los niños abandonados ${ }^{7}$, fueron objeto de una definida política asistencial. Con ella la caridad trascendía los límites de las instituciones privadas que se habían ocupado de paliarla, para convertirse en parte de las competencias del Estado. Buena prueba de ello es la fundación de instalaciones hospitalarias de carácter general, que convivieron con la red de pequeños y medianos hospitales, cuyo mapa se configuró a lo largo de la Edad Media. Sin embargo, pese a la implementación de un sistema asistencial estatal para la atención de los grupos sociales más desfavorecidos económicamente, la Iglesia siguió cumpliendo con sus obligaciones caritativas impuestas por la doctrina cristiana, que el Concilio de Trento definió con mayor precisión $^{8}$. En estas instituciones el expósito recibía atención material (comida, cama y

García Jiménez, B.: Demografía rural andaluza: Rute en el Antiguo Régimen, Córdoba, Diputación provincial, 1987, p. 246.

4 León Vegas, M.: "Un estudio de caso sobre abandono infantil en la Andalucía Moderna: los expósitos de la inclusa antequerana”, Revista de Demografia Histórica, 33 (2015), p. 124.

5 Prueba de su discriminación es su exclusión de determinados ejercicios profesionales hasta finales del siglo XVIII, o su explotación laboral en algunos casos: Martínez Carrión, J.M.: El nivel de vida en la España rural, siglos XVIII-XIX, Alicante, Universidad, 1997, p. 497. Iturralde Valls, M.: "El trabajo infantil en las fábricas indianas, 1736-1800", Revista de Historia industrial, 68 (2017), pp. 13-46. Acuña León, M.A. y Chavarría López, D.: "Mestizos, mulatos y zambos en la ciudad de Cartago (siglo XVIII), Revista de Historia, 77, (2018), p. 138.

6 Bartolomé Martínez, B.: "La crianza de los expósitos en España entre la Ilustración y el Romanticismo (17901835)", Historia de la Educación: Revista Interuniversitaria, 10 (1991), pp. 33-34.

Ariès, P.: L'Enfant et le vie familliale sous l'Ancien Régime, París, Plon, 1960, pp. 441-445.

8 Coronel Ramos, M. A.: "La caridad: voces de reforma del clero en el siglo XVI", Studia Philologica Valentina, 
atenciones médicas) y espiritual, pues de la cura animorum se encargaban clérigos que les administraban los sacramentos, entre ellos el bautismo ${ }^{9}$.

Los estudios sobre el sistema asistencial español, sin pretender realizar un estado de la cuestión exhaustivo, se han multiplicado gracias, en buena medida, al desarrollo del análisis de los grupos marginados a partir de la moderna historiografía local y la sociología histórica. A nivel general destacan las obras de Rumeu de Armas ${ }^{10}$, López Yepes ${ }^{11}$, Carreras Pachón ${ }^{12}$, o Carmona García ${ }^{13}$. Distintas ciudades cuentan con estudios propios, la gran mayoría centrados en el siglo XVIII, como Andújar ${ }^{14}$, Granada $^{15}$, La Coruña ${ }^{16}$, Madrid ${ }^{17}$, Mallorca ${ }^{18}$, Pamplona ${ }^{19}$, Salamanca ${ }^{20}$, Santiago de Compostela ${ }^{21}$, Úbeda ${ }^{22}$, Valladolid ${ }^{23}$ o Zaragoza ${ }^{24}$. Y fuera de España hemos de reseñar los trabajos para Ámsterdam ${ }^{25}$, Augsburgo ${ }^{26}$, Florencia y Bolonia ${ }^{27}$, Leiden ${ }^{28}$, el norte de Francia ${ }^{29}$ y Utrecht ${ }^{30}$.

1 (2013), pp. 182-184.

9 Álvarez Santaló, L.C.: Marginación social y mentalidad en Andalucía Occidental: expósitos en Sevilla (16131910), Sevilla, Consejería de Cultura de la Junta de Andalucía, 1980, p. 19.

10 Rumeu de Armas, A.: Historia de la previsión social en España. Cofradias, Gremios, Hermandades, Montepíos, Barcelona, El Albir, 1981.

11 López Yepes, J.: Historia de los Montes de Piedad en España, Madrid, Universidad Complutense, 1971.

12 Carreras Pachón, A.: El problema del niño expósito en la España ilustrada, Salamanca, Universidad, 1977.

13 Carmona García, J. I.: "La quiebra de las instituciones benéficas como reflejo de la crisis económica del siglo XVIII", Archivo Hispalense, 195 (1981), pp. 155-176.

14 Gómez Martínez, E.: Los niños expósitos en Andújar, Córdoba, Universidad, 1987.

15 De la Fuente Galán, M. P. “La creación del Hospicio de Granada”, Publicaciones, 25-27 (1996), pp. 141-160.

16 López Picher, M.: "Los primeros años de la inclusa de La Coruña, bajo el patronato de la venerable Congregación del Divino Espíritu Santo y María Santísima de los Dolores (1739-1799)”, en La Iglesia española y las instituciones de caridad, El Escorial, Ediciones Escurialenses, 2006, pp. 579-616.

17 Demerson, P.: "La Real Inclusa de Madrid a finales del XVIII", Anales del Instituto de Estudios Madrileños, VIII (1972), pp. 261-272.

18 Pascual Ramos, E.: "Hospicios y expósitos en Mallorca durante el siglo XVIII (1701-1811), en Saitabi, 66 (2016), pp. 101-119.

19 Valverde Lamfus, L.: "Los niños guipuzcoanos en la inclusa de Pamplona en el siglo XVIII”, Bilduma, 1 (1987), pp. 109-128.

20 Fernández Ugarte, M.: Expósitos en Salamanca a comienzos del siglo XVIII, Salamanca, Diputación, 1988.

21 Eiras Roel, A.: "La Casa de Expósitos del Real Hospital de Santiago en el siglo XVIII", Boletín de la Universidad Compostelana, 75-76 (1967), pp. 295-335.

22 Tarifa Fernández, A.: "La infancia marginada en la Edad Moderna: los niños expósitos de Úbeda", Andalucía en la Historia, 1 (2003), pp. 62-68.

23 Egido, T.: “Aportación al estudio de la demografía española: niños expósitos de Valladolid (siglos XVI-XVIII)", en Actas de las I Jornadas de Metodología aplicada de las ciencias históricas, Santiago de Compostela, Universidad, 1975, pp. 333-346. Zorrilla, E.: Valladolid: sus pobres y la respuesta institucional (1750-1900), Valladolid, Universidad, 1985.

24 Baquero, A.: Bosquejo histórico del Hospital Real y General de Nuestra Señora de Gracia de Zaragoza, Zaragoza, Institución "Fernando el Católico", 1952.

25 McCants, A.: Civic charity in a Golden Age. Orphan care in Early Modern Amsterdam, Chicago, University of Illinois Press, 1997.

26 Safley, T. M.: Charity and economy in the orphanages of early modern Augsburg, Boston: Humanities Press, 1997.

27 Terpstra, N.: Abandoned Children of the Italian Renaissance: Orphan Care in Florence and Bologna, Baltimore, Johns Hopkins University Press. 2005

28 Schmidt, A.: "Managing a large household. The gender division of work in orphanages in Dutch towns in the early modern period,1580-1800”, History of the Family, 13 (2008), pp. 42-57.

29 Ryckebusch, O.: Les hôpitaux généraux du Nord au siècle des Lumières (1737-1789), Villeneuve d'Ascq, Presses Universitaires du Septentrion, 2017.

30 Schalk, R.: "From orphan to artisan: apprenticeship careers and contract enforcement in The Netherlands before and after the guild abolition", The Economic History Review, 70 (2017), pp. 730-757. 
En el caso de nuestro ámbito de estudio, Sevilla, contamos con los trabajos de Álvarez Santaló ${ }^{31}$. En ellos realiza un estudio sistemático de la documentación del archivo de la Casa Cuna hispalense, concretamente de los libros de ingresos desde 1613 y el libro de protocolos. Nuestro trabajo quiere ser un complemento a dichos estudios, analizando los libros de bautismo que sobre los niños abandonados se conservan en la parroquia de Santa María Magdalena. Los libros de bautismo constituyen una de las fuentes principales para conocer las sociedades del pasado y son el resultado del proceso de reafirmación de la Iglesia de Roma que supuso el Concilio de Trento ${ }^{32}$. Durante el mismo se definió, entre otras, la doctrina fundamental de este sacramento, al que le fue reservado un lugar de especial relevancia (de hecho, varias confesiones reformadas continuaron considerándolo un sacramento $)^{33}$. De las múltiples parroquias de la urbe, se destaca la de Santa María Magdalena, debido a que en ella se hallaba la Cofradía de Nuestra Señora del Amparo, cuya obra asistencial supuso la génesis de la Casa Cuna en esta ciudad.

Metodológicamente hablando, se ha realizado un análisis sistemático de los libros que contienen las partidas de bautismo, haciendo acopio de la información contenida en dichas partidas y extrayendo todos los datos de las correspondientes a los expósitos. Estos libros recogen información acerca del neófito y del rito en sí mismo. Junto al nombre del niño, encontramos un texto que contiene la fecha en la que este recibe el bautismo (día, mes y año). A continuación, se indica quién le administra el sacramento, su rango dentro de la jerarquía eclesiástica y su grado de orden presbiteral. También vuelve a aparecer el nombre con el que el neófito es bautizado y se indica el nombre de sus padres (no en el caso de los expósitos). Finalmente, se cierra siempre con una fórmula por la que se establece el parentesco espiritual entre el niño y su padrino. La imposibilidad física de analizar todo el volumen documental del fondo nos ha llevado a inclinarnos por un sistema de sondeo de años que consideramos significativos, concretamente de dos períodos: 1597-1611, por la relevancia que tiene el final de un siglo y el comienzo de otro; y de 1647 a 1652, lustro especialmente interesante por la incidencia de la epidemia de peste. Se trata, pues, de un muestreo de períodos más o menos extensos constituidos por un total de 5600 partidas de bautismo. Las bases de datos en las que nos hemos basado para la realización de estadísticas y su reflejo en las gráficas han sido diseñadas a partir de variables como el número de bautizados, el número de expósitos bautizados y la proporción de los mismos en los distintos períodos, los meses en los que se da un mayor número de exposiciones, la frecuencia de nombres de los neófitos y el número de padrinos con los que estos establecen parentesco espiritual.

31 Álvarez Santaló, L. C.: "La Casa de expósitos de Sevilla en el siglo XVII", en Cuadernos de Historia del Instituto Jerónimo Zurita, VII (1977), pp. 491-532; Marginación social y mentalidad en Andalucía occidental: expósitos en Sevilla (1613-1910); La beneficencia sevillana en el tránsito del Antiguo al Nuevo Régimen, Sevilla, Universidad, 1981.

32 Alfani, G. y Gourdon, V. (eds.): Spiritual Kinship in Europe, 1500- 1900, Hampshire, Palgrave MacMillan, 2012, pp. 55-56.

33 Irigoyen López, A., Ghirardi, M., Sartori, F.: "Bautismo y padrinazgo en la ciudad de Córdoba (1691-1775)", en Familias históricas. Interpelaciones desde perspectivas Iberoamericanas través de los casos de Argentina, Brasil, Costa Rica, España, Paraguay y Uruguay, Saõ Leopoldo Oikos-Editora Unisinos, 2015, pp. 19-36. 


\section{Sevilla a finales del siglo XVI y la primera mitad del XVII}

Sin que sea nuestra intención hacer una exposición exhaustiva del contexto histórico en el que se centra nuestro estudio, consideramos necesarias unas breves pinceladas sobre la Sevilla de finales del siglo XVI y la primera mitad del XVII. La ciudad de Sevilla, desde el Descubrimiento de América, se convirtió en un enclave principal y primordial, especialmente por ser las aguas del río Guadalquivir, navegables hasta la ciudad del Betis. Este hecho favoreció que el tráfico de embarcaciones que entraban y salían del principal puerto de la Corona de Castilla desde y hacia las Indias fuera muy intenso. De hecho, los Reyes Católicos decidieron instalar en esta ciudad la Casa de la Contratación de Indias, con la repercusión que tuvo dicha acción para la urbe y sus habitantes. La elección de Sevilla como sede de la Casa de la Contratación fue fruto, precisamente, de las características de la ciudad ${ }^{34}$, un hecho de gran importancia, ya que llegó a afectar durante siglos e, incluso, hasta hoy en la forma de ser de la ciudad, sus construcciones y sus gentes. Estos acontecimientos hicieron de Sevilla una de las más importantes ciudades a nivel europeo, según Menéndez Pidal y Núñez Roldán ${ }^{35}$. A las dos anteriores, hemos de sumar otras voces, como la de Pérez-Mallaína Bueno, quien señala a Sevilla como conexión entre el Viejo y el Nuevo Mundo. De hecho, habla de España como "puente"36 entre ambos continentes y su comienzo se encontraba en la ciudad andaluza.

Sevilla experimentó un incremento importante de sus habitantes desde comienzos del siglo XVI hasta finales de este mismo siglo. Así, según las cifras que podemos manejar en función de los datos disponibles, podemos apreciar un incremento ya en la década de 1570. De hecho, la población rondaba los 50000, siendo 21000 el total de vecinos de la ciudad ${ }^{37}$, en comparación con los aproximadamente 9000 que vivían en el año 1530, de acuerdo con el Censo de población de las provincias y partidos de la Corona de Castilla en el siglo XVI ${ }^{38}$. Es lo que confirma Andrea Navagero ${ }^{39}$, por aquel entonces embajador de la República de Venecia. Este, tras una visita a la ciudad en el año 1526, dejó por escrito que muchas eran las personas que en aquella fecha abandonaban estas tierras para viajar al Nuevo Mundo. Los aproximadamente 50000 habitantes que señalábamos unas líneas más arriba llegaron casi a doblarse a finales del mismo siglo ${ }^{40}$. Para entonces, a finales del XVI, la población de Sevilla rondaba los 120000 habitantes, una tendencia que estaba claramente al alza a medida que avanzaba dicho siglo ${ }^{41}$.

34 Serrera Contreras, R. M.: "La Casa de la Contratación en el Alcázar de Sevilla (1503-1717)", Boletín de la Real Academia Sevillana de Buenas Letras, 36 (2008), pp. 133, 137.

35 Menéndez Pidal, R.: "La crisis del siglo XVII. La población, la economía, la sociedad", en Historia de España. Madrid, Espasa-Calpe, 1996, pp. 99-102. Núñez Roldán, F.: La vida cotidiana de la Sevilla del Siglo de Oro, Madrid, Sílex, 2004, p. 9.

36 Pérez-Mallaína Bueno, P. E.: "Sevilla centro de la Carrera de Indias y de la náutica española en el siglo XVI", en Actas de las II Jornadas de Andalucía y América, v. 1, Sevilla, Universidad de Sevilla, 1983, p. 307.

37 Pérez García, R. M.: "La población del reino de Sevilla en 1571 y las consecuencias demográficas de la guerra de Granada". Archivo Hispalense, 279-281 (2009), p. 151.

38 Instituto Nacional de Estadística (INE): Censo de población de las provincias y partidos de la Corona de Castilla en el siglo XVI. Fol. 84.

39 Pozo Ruiz, A.: "Demografía de Sevilla en el siglo XVI", en De cómo creció la población sevillana. https:// personal.us.es/alporu/histsevilla/poblacion.htm [consulta: 30 de enero de 2020].

40 Morales Padrón, F.: "La historia de Sevilla de Luis Peraza", Boletín de la Real Academia Sevillana de Buenas Letras: Minervae Baeticae, 6 (1978), p. 80.

${ }^{41}$ Lacomba Abellán, J. A.: "Las desigualdades interiores en Andalucía en perspectiva histórica. Una aproximación”, Revista de estudios regionales, 54 (1999), pp. 318-319. 
En cuanto a la formación de la ciudad y su distribución, se daba la situación de que personas de distintos estamentos y posibilidades económicas convivían en los mismos barrios. Aun así, existían áreas con una mayor proporción de viviendas de personas con menos posibilidades económicas. Se trataba de la mayor parte de la población, casi todos ellos jornaleros, cuyas viviendas pertenecían, en gran medida, a la Iglesia ${ }^{42}$. Dentro de los estratos de la sociedad que poseían las mejores casas, encontramos a los jurados, a los veinticuatros, de linaje noble estos últimos, que desempeñaban cargos del gobierno municipal, y los que se dedicaban a actividades vinculadas al comercio ${ }^{43}$.

La diferencia entre los distintos grupos era evidente: viviendas de poca calidad frente a grandes casas y palacios. Gran parte de estos pertenecían a mercaderes, concentrados de manera más notable en la collación de Santa María o Santa María la Mayor, es decir, la Catedral. Todo esto sucedía en un contexto en el que el número de personas pudientes aumentaba, a la vez que veían el incremento de sus bienes e ingresos desde el comienzo del siglo XVI hasta mediados del XVII ${ }^{44}$. En relación con los mercaderes, se encontraban desde burgaleses hasta portugueses ${ }^{45}$, genoveses ${ }^{46} \mathrm{y}$ flamen $\cos ^{47}$. Estos estaban presentes en los lugares de mayor importancia comercial y, por su puesto, uno de ellos era Sevilla ${ }^{48}$.

Aparecen estas circunstancias también en un contexto en el que la ciudad estaba dividida, a finales del siglo XVI, en un total de veintinueve collaciones. Estas se organizaban en torno a las parroquias, que fueron un total de veintisiete a lo largo de este siglo y que, a finales de este, sumó dos más. La collación era una división de gran relevancia en el momento, como podemos comprobar en el hecho de que se debía indicar la collación de la que se procedía, tal y como ocurría en el caso de los libros de bautismo. En ellos se especificaba, en la inmensa mayoría de los casos, la collación de la que procedían los padrinos del neófito.

En esta misma fecha, la ciudad contaba con una muralla con diversas puertas. Todas ellas se cerraban al caer la tarde y volvían a abrirse al amanecer, no solo por materia de seguridad y, así, controlar los productos que se introdujeran y sus impuestos correspondientes ${ }^{49}$. También tenían gran valor a la hora de intentar contener las enfermedades que se produjeran. Es el caso de las pestes, otra de las causas por las que las puertas controlaban la entrada y salida tanto de personas como de productos.

42 Bernales Ballesteros, J.: "El urbanismo sevillano de los siglos XVI-XVII", en Historia del urbanismo sevillano. Sevilla, C. S. I. C. (Patronato José María Cuadrado), 1972.

43 Girón Pascual, R.M.: "Mercaderes de seda, 'verlegers' y veinticuatros: los Castellano de Marquina de Granada (1569-1644)", en Comercio y cultura en la Edad Moderna Sevilla, Sevilla, Universidad de Sevilla, 2015, pp. 406-410.

44 Cartaya Baños, J.: Mayorazgo., Riqueza, nobleza, y posteridad en la Sevilla del siglo XVII, Sevilla, Universidad de Sevilla, España, 2018.

45 Fernández Chaves, M.F. y Pérez García, R.M.: "La penetración económica portuguesa en la Sevilla del siglo XVI", Espacio, Tiempo y Forma, Serie IV, Historia Moderna, 25 (2012), pp. 200-201.

46 Herrero Sánchez, M. (coord..): Génova y la monarquia hispánica (1528-1713), Génova: Societá Ligure di Storia Patria, 2011, p.

47 Díaz Blanco, J. M.: "La construcción de una institución comercial: el consulado de las naciones flamenca y alemana en la Sevilla moderna", Revista de Historia Moderna Anales de la Universidad de Alicante, 33 (2015), p. 125 .

48 Pérez García, R. M.: "Mercaderes burgaleses en la Andalucía de los siglos XVI y XVII: Procesos de enriquecimiento, ascenso social y ennoblecimiento", en Monarquías en conflicto. Linajes y noblezas en la articulación de la Monarquía Hispánica, Madrid, Fundación Española de Historia Moderna, 2018, p. 618.

49 Del Pozo y Barajas, A.: Sevilla. Elementos de análisis urbano, Sevilla, Universidad de Sevilla, 2003. 
Sin embargo, a pesar de las medidas que se tomaron para intentar frenar las epidemias, estas no fueron suficientes. Esta situación llevó a la proliferación de la peste entre los habitantes de la ciudad de Sevilla, no solo en esta fecha, en 1582, sino que la situación se repitió, con una nueva epidemia de peste, justo en las postrimerías del XVI, concretamente en el $1599^{50}$.

A las enfermedades hay que sumarles las no pocas crecidas del río Guadalquivir, lo que conocemos como las riadas. Se sabe que en el período que abarca desde el 1504 hasta el 1596, se produjeron un total de dieciséis ${ }^{51}$. Sin embargo, no fueron aisladas ni exclusivas de dicho siglo, sino que en el XVII, concretamente el 25 de enero de 1626, se dio una inundación tan importante que llegó a alcanzar las zonas de las collaciones del centro y del suroeste. De hecho, en un trabajo de Díaz Peña, podemos leer cómo este se refiere a este año como "el del diluvio" 52 . Así, podemos ver el río como fuente de las riquezas tanto económicas como culturales, tal y como afirma Zamora Rodríguez, que se generaban del comercio con las Indias pero, a la vez, como fuente de desastres naturales. Por tanto, estamos antes una ciudad muy potente económicamente pero, como contraposición, una ciudad débil ante epidemias, riadas, o crisis agrarias, que abocaban a la pobreza y la marginación a los grupos más desfavorecidos, explicando mucho casos de abandonos de niños.

\section{Análisis de los registros bautismales de los expósitos sevillanos}

Hemos de comenzar señalando cómo se identifica a esos niños que fueron expuestos. En todas las partidas de bautismo registradas se recogían el nombre del neófito, el de sus padres, el del eclesiástico que lo bautizó y el del padrino. Sin embargo, en el caso de los expósitos, no era posible escribir el nombre de los padres, ya que estos eran desconocidos. Es por ello por lo que estos niños eran inscritos en los libros bautismales como "hijos de la Iglesia, hijos de Dios y de santa María, hijos de la santa madre Iglesia, o hijos de la Cuna"53. Estas denominaciones fueron variando a lo largo de los años estudiados hasta llegar al momento en el que se usaban unas u otras indistintamente. Lo observamos en los neófitos del año 1597, cuya denominación es en su mayoría la de "hijo de Dios y de santa María" 54 . En los años posteriores, a partir de $15999^{55}$, se ve cómo aumenta la tendencia a intercalar las denominaciones de "hijo de Dios y de santa María" e "hijo de la Iglesia". Esta última es la denominación más extendida a partir de $1601^{56}$. Además, destaca el uso de la denominación "hijo de la santa madre Iglesia" a partir del segundo período estudiado (1604-1611). Concretamente, lo encontramos en

50 Arráez Tolosa, A.: "El paso de la epidemia de la peste atlántica de 1596-1602 por Almansa", Al-Basit: Revista de estudios albacetenses, 63 (2018), p. 193.

51 Peña Díaz, M.: "El Guadalquivir: Sueños y representaciones en el Siglo de Oro", E-Spania. 2015, p. 6. https:// journals.openedition.org/e-spania/24440 [Consulta: 20 de febrero de 2020].

52 Zamora Rodríguez, F.: "Quando el agua llegare aquí Sevilla...". La avenida del río Guadalquivir en 1626 según un documento de la Biblioteca de Ajuda (Portugal), Lisboa, Centro de História, 2014, p. 408.

53 Archivo de la Parroquia de Santa María Magdalena de Sevilla: libros bautismales 1597-1603 y 1604-1611. En adelante indicaremos el libro y los folios.

54 Libro 1597-1603, fols. 7v-61v.

55 Ibidem, 137r-394v.

56 Ibidem, 248r-394v. 
1608, año en el que su uso estuvo muy extendido ${ }^{57}$. Quizás fue consecuencia de la influencia del Concilio de Trento en Sevilla. Es en este punto en el que hay que recordar la celebración en 1604 del Sínodo diocesano en Sevilla ${ }^{58}$, mediante el cual se implantaron las decisiones tridentinas en la archidiócesis, presidido por el arzobispo Fernando Niño de Guevara ${ }^{59}$. Dicho Sínodo instaba a tener registros más rigurosos de aquellos que recibían los sacramentos, especialmente el que los introducía en la comunidad cristiana, es decir, el bautismo ${ }^{60}$. En cuanto a las denominaciones de los expósitos, fue a partir de 1647 cuando observamos la denominación "de la Cuna", como podemos ver en los registros del libro de los años 1647 a $1652^{61}$.

\section{El primer período (1597-1611)}

En primer lugar, haremos un análisis más global, señalando el número total de niños bautizados entre los años 1597 y $1611^{62}$, ambos incluidos. Más tarde, iremos desgranando estos datos por partes dentro de este período más largo. En este, fueron bautizados un total de 3846 niños, de los cuales 463 eran expósitos. Estos números suponían que dentro de este período de 15 años hubo un 12\% de expósitos bautizados. Es lo que podemos observar en la siguiente gráfica.

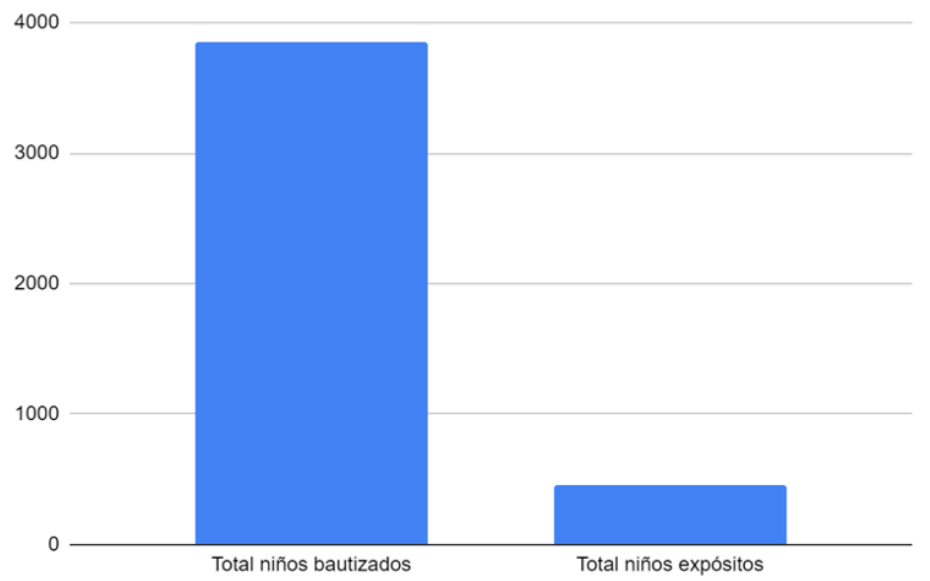

Si dividimos estos datos en dos períodos (1597-1603 y 1604-1611), división que viene dada por la propia organización de los libros, ya que los registros están en dos

\footnotetext{
Libro 1604-1611, fols. 223v-284v.

58 Sánchez Herrero, J.: Synodicon Baeticum I. Constituciones conciliares y sinodales del Arzobispado de Sevilla, t. I: años 1590-1604, Sevilla, Universidad de Sevilla, 2007, pp. 197-199.

59 Martín Riego, M.: "Enseñanza y clero parroquial en la Archidiócesis de Sevilla (1750-1800)", Escuela Abierta, 5 (2002), pp. 222-224.

60 Constituciones del Arzobispado de Sevilla, Hechas y Ordenadas por el Ilustrísimo y Reverendísimo Señor Don Fernando Niño de Guevara, Cardenal y Arzobispo de Sevilla, en el Sínodo que celebraron en su Catedral el año de 1604. Sevilla, 1609, por Alonso Rodríguez Gamarra, fols. 32v-33r.

61 Libro 1647-1653, fol. 28r-74r.

62 Ibidem.
} 
libros, uno de 1597 a 1603 y otro de 1604 a 1611, podemos ver cómo los datos que se recogen en uno y en otro son muy similares. Son parecidos en cuanto al porcentaje de varones en el primer y segundo períodos, al igual que ocurre con el de las niñas. Este porcentaje apenas varía. De hecho, entre 1597 y 1603, se les administró el bautismo a un $55 \%$ de varones y a un $45 \%$ de niñas ${ }^{63}$. A su vez, en el período de 1604 a 1611 , se dio un $56 \%$ de bautismos de varones y un $44 \%$ de niñas ${ }^{64}$. Lo mismo sucede con respecto al sexo de los expósitos ${ }^{65}$.

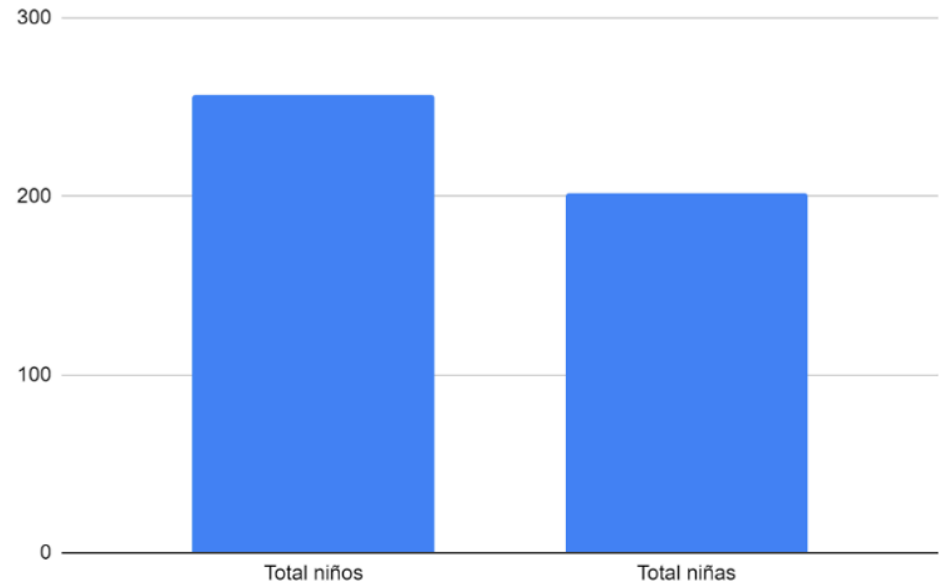

En los años comprendidos entre 1597 y 1603, la tendencia del número de expósitos era considerablemente alta en comparación con lo que se puede observar en el siguiente período ${ }^{66}$. Contrasta, por lo tanto, con la tendencia a la baja de expósitos que se dio en el período comprendido entre 1604 y $1611^{67}$. A pesar de tener este período un año más que el anterior, la media de bautizos total fue menor, al igual que el número de expósitos. En la siguiente gráfica se puede observar con mayor claridad esta tendencia, en la cual se aprecia que, del primer período, el máximo de expósitos en un año fue de 50, concretamente en $1598^{68}$. Esta tendencia de expósitos al alza a finales de siglo aminoró el ritmo al comienzo de la nueva centuria. Así, el número mínimo de expósitos fue en estas fechas de 30 en un año, en $1600^{69}$. Si bien es verdad que hubo años en los que se dieron repuntes, estos no fueron tan altos como en los años anteriores, como ocurrió en 1602, año en el que se contaron 42 expósitos $^{70}$. En el caso del segundo período, el año con más expósitos fue 1608 , con un total de $37^{71}$, lo que contrasta con el máximo del anterior período, que fue de 50. Esta información se refleja en las dos gráficas siguientes.

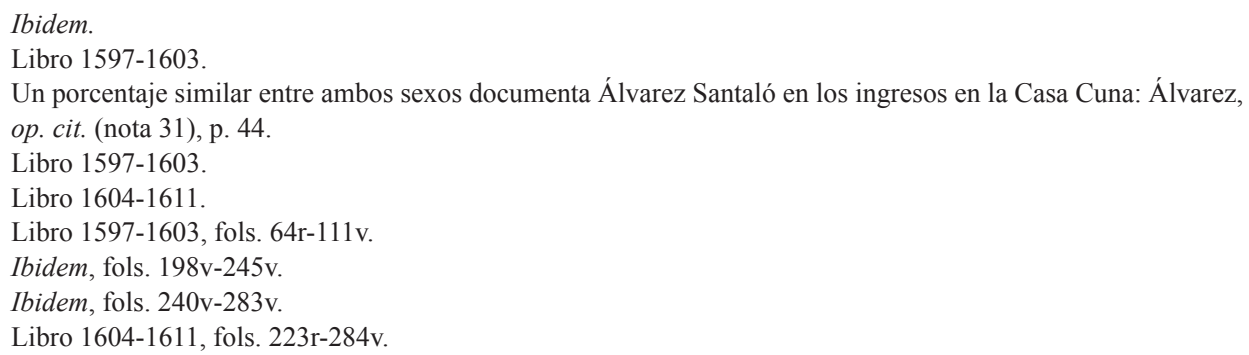



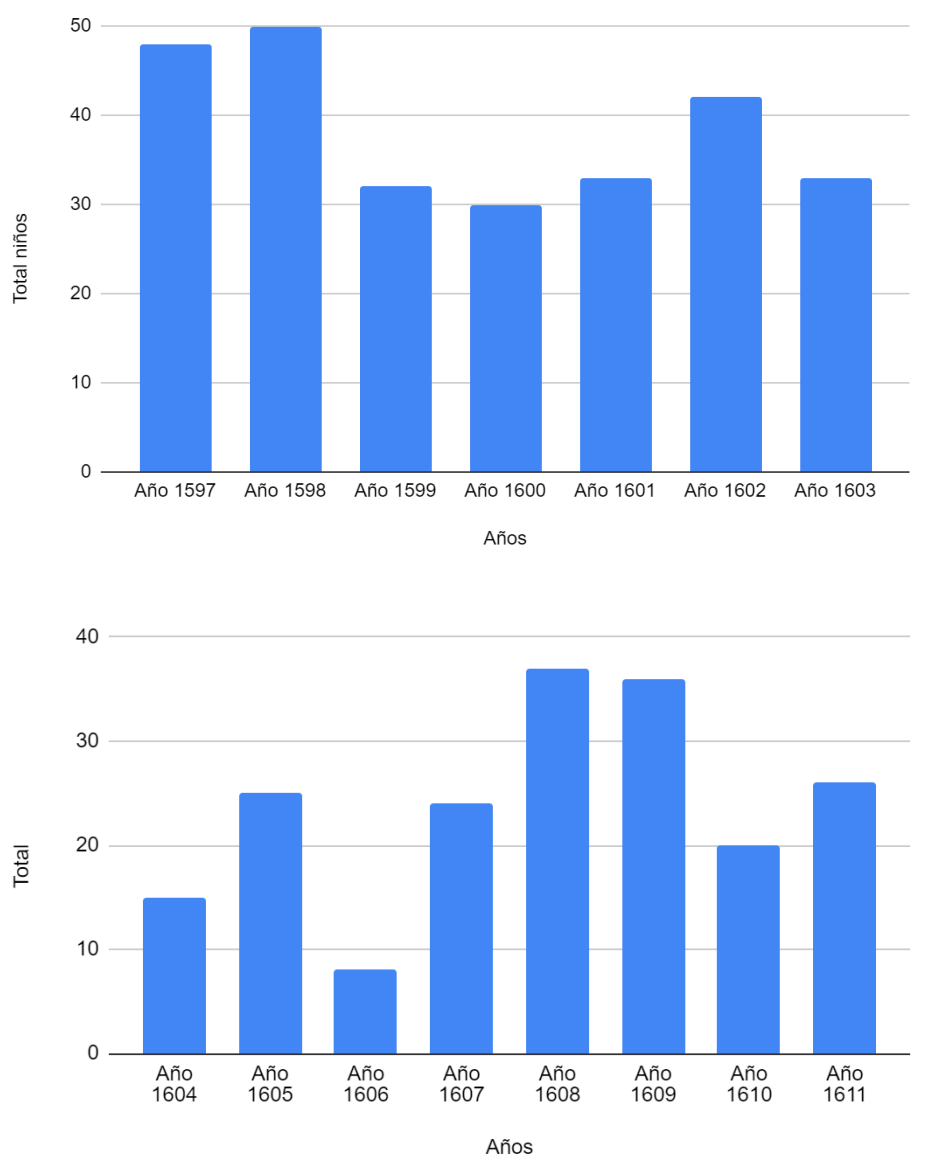

Así, en caso de hablar del porcentaje total de cada período, estos fueron un $14 \%$ en el primero ${ }^{72}$ y un $9 \%$ en el segundo ${ }^{73}$, lo que confirma las afirmaciones anteriores sobre un mayor número de expósitos en el período entre 1597 a 1603 que en el correspondiente a los años 1604-1611 ${ }^{74}$. Ambos períodos juntos supusieron un 12\%.

Entre los datos que podemos hallar en los libros de bautismo de esta época se encuentran el nombre de los padrinos y su procedencia ${ }^{75}$. Cobró especial relevancia el papel de estos tras el Concilio de Trento, que afirmaba que el parentesco espiritual se establece entre el neófito, sus padres, el padrino y el ministro que bautizaba ${ }^{76}$. De ahí la importancia de los padrinos. Hay que destacar que en esta parroquia la mayoría de ellos eran, como cabía esperar, de la collación de la Magdalena. Se explica

\footnotetext{
Libro 1597-1603.

Libro 1604-1611.

Libros $1597-1603$ y $1604-1611$.

Libros 1597-1603, 1604-1611 y 1647-1655.

76 Un interesante estudio sobre las redes de carácter espiritual que unía a las familias con los padrinos de los hijos es: Carvalho, J. y Ribeiro, A. I.: "Using network analysis on parish registers: How spiritual kinship uncovers social structure", en Bridging the Gaps: Sources, Methodology and approaches to Religion in Europe, Edizioni Plus, Pisa, 2008, pp. 171-186.
} 
por el hecho de que este registro de bautismos es de la parroquia homónima ${ }^{77}$. Sin embargo, también hubo un alto número de padrinos que procedían de la collación de Santa María, es decir, de la Catedral, aunque su número estaba muy por debajo de los primeros. El total de padrinos de la collación de la Magdalena fue de 177 en el período comprendido entre 1597 y $1603^{78}$, mientras que en el que va de 1604 a 1611 fueron un total de $57^{79}$. No obstante, es destacable que a partir de 1608 se dejó de anotar en la mayoría de los casos la procedencia de los padrinos. El primer padrino cuyo origen no se registró es el de la niña expósita Juana, bautizada el domingo 20 de enero de 1608 por Juan Adame. Su padrino fue Antón Martínez ${ }^{80}$. A partir de esta fecha, solo conocemos el origen de algunos de los padrinos.

Encontramos un ejemplo de expósitos de cuyo padrino sí se anotaban datos en el último año del período, en 1611. Se trata de una niña expósita, Magdalena, bautizada el sábado 30 de julio de 1611 por Juan Adame. Su padrino fue Pedro de Velasco, vecino de San Vicente ${ }^{81}$. Lo hacían también en el caso de que el padrino perteneciera al clero, indicando que era presbítero, diácono o con cualquier otra orden. Un ejemplo es el licenciado Cristóbal de San Juan, de quien se afirma que era "presbítero y capellán de esta iglesia"82. Otro supuesto era el de ser presbítero de otra collación. Al respecto, podemos señalar que se anotaba si este era capellán de otra parroquia o la collación en la que vivía. Es el caso del licenciado de Galves, de quien se indica que era "presbítero, vecino de San Vicente y capellán de esta iglesia"83. Se anotaban también los cargos de cada presbítero y sus funciones. Es el caso del colector o capellán. La del colector era una figura administrativa de la parroquia que podía ser un clérigo o un seglar y que se encargaba de comprobar que se celebraban las misas encargadas por el sufragio de las almas de los difuntos. Era responsable del control de las misas, las limosnas, los estipendios e, incluso, de los bienes que el difunto dejaba en herencia a la iglesia para la celebración de misas para la salvación de su alma ${ }^{84}$. El capellán era el que se encargaba de la administración de una capellanía, fundada por una persona o por una familia para sus bien espiritual, especialmente para el ofrecimiento de oraciones, la misa ${ }^{85}$, para gozar de las alegrías eternas con un paso rápido por el Purgatorio ${ }^{86}$. Anotado como colector quedó el licenciado Rodrigo de Guevara, padrino de Lucía Jerónima, que fue bautizada el 18 de diciembre de 1610 por Juan Adame $^{87}$. También se indicaban las profesiones más importantes, como en la partida de bautismo de Alonso, quien recibió las aguas bautismales el viernes 6 de noviembre de 1609, de manos del Licenciado Rodrigo de Guevara, capellán y colector de

\footnotetext{
Libros $1597-1603$ y 1604-1611.

Libro 1597-1603.

Libro 1604-1611.

Ibidem, fol. $223 \mathrm{v}$.

Ibidem, fol. 426v.

Ibidem, fol. $397 \mathrm{v}$.

Ibidem, fol. 232r.

Calvo Ruiz, M.: "Análisis de una defunción en los siglos XVII-XVIII a través de las anotaciones contables que realizaban el colector parroquial”, Tiempos Modernos, 15 (2007), pp. 3-4.

85 Castro Pérez, C.: "Las capellanías en los siglos XVII-XVIII a. través del estudio de su escritura de fundación", Anuario de Historia de la Iglesia, 16 (2007), pp. 336-337.

86 Benítez Blanco, V.: "Iconografía del purgatorio en las iglesias y conventos de Madrid", en El mundo de los difuntos: culto, cofradias y tradiciones. Vol. 1, Madrid, Ediciones Escurialenses, 2014, p. 563.

87 Ibidem, fol. 392r.
} 
esta iglesia. Su padrino fue Diego Díaz Castillejo, escribano de justicia del rey ${ }^{88}$. La importancia de esta profesión derivaba de la responsabilidad de las funciones que los escribanos reales desempeñaban, ya que ellos eran los que poseían la facultad de autorizar los procesos judiciales en todo el territorio correspondiente al reino ${ }^{89}$.

Con respecto a la procedencia de los padrinos, podemos ver en la siguiente gráfica los datos ya ofrecidos acerca del número de aquellos que pertenecían a la collación de la Magdalena y a la de la Catedral. Hay que tener en cuenta que dicha gráfica recoge la información de un período de 15 años (1597-1611) divido en dos. El primero, comprendido hasta 1603 y, el segundo, de 1604 a 1611, por lo que hay que tener en cuenta que el número de padrinos que van a aparecer será menor en el segundo período, debido a la tendencia ya apuntada de no anotar la procedencia de la mayoría de los padrinos a partir de 1608 .

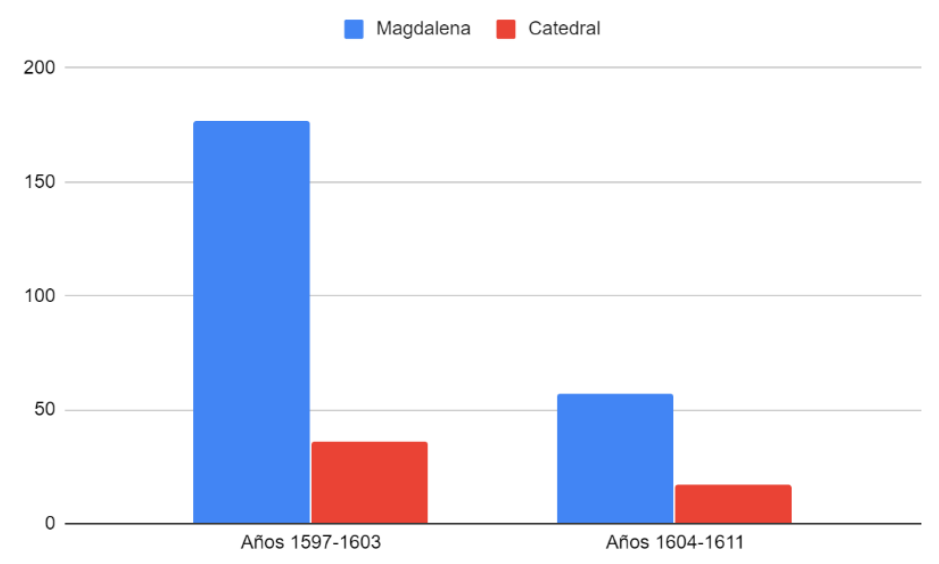

En estos años, podemos observar también cómo algunos niños tenían tanto padrino como madrina. Esta es una opción contemplada por Trento, ya que establecía que los padrinos serían máximo un hombre o un hombre y una mujer ${ }^{90}$, aunque esta última se trata de una práctica habitual que ya podía verse desde la Edad Media, donde podían darse casos de hasta dos padrinos y dos madrinas. Podemos conocer estos datos por los sínodos de Sevilla de 1490, de Jaén de 1492 y de Córdoba de $1520^{91}$. Se registraron un total de 18 expósitos en este escenario ${ }^{92}$. En la mayoría de los casos, parece que no tenían vínculos que los unieran entre sí, ya que en muchas ocasiones el padrino procedía de una collación y la madrina venía de otra distinta. Ocurre esto con Juan, bautizado por Juan Moreno de Castañeda el sábado 31 de mayo de 1597. Sus padrinos fueron Cristóbal Martín, vecino de Triana, y doña Isabel Ponce, vecina de la Magdalena ${ }^{93}$.

\footnotetext{
Ibidem, fol. 330r.

89 Esteves Santamaría, M. P.: “Transmisiones de escribanías en Madrid (siglos XVI-XIX)”, Cuadernos de Historia de Derecho, 7 (2000), p. 132.

90 Constituciones del Arzobispado, op. cit. (nota 59), fol. 32v.

91 Pérez González, S. M. y Arboleda Goldaracena, J.C.: "Mujeres e Iglesia en Andalucía a finales de la Edad Media", en Actas de la I Jornada de Historia en Conmemoración del 50 Aniversario del fallecimiento de don Hipólito Sancho, Jerez de la Frontera, Centro de Estudios Históricos Jerezanos, 2016, p. 132.

92 Libros $1597-1603$ y $1604-1611$.

93 Libro 1597-1603, fol. 26v.
} 
Esta situación parece indicar que no existían vínculos entre ambos padrinos, ya que no se señalaba qué relación existía entre ellos. Sin embargo, cuando era un matrimonio sí se dejaba constancia de ello. En relación con el resto de los casos, podemos decir que no existía relación alguna o bien que no se anotaba otra que no fuera el matrimonio. Es el caso de Andrés de Escobar e Inés Tomasina. De esta se indica que es "su mujer". Ambos fueron padrinos de Francisca Andrea, bautizada el 14 de febrero de $1600^{94}$. Además, cabe destacar los datos que se ofrecen sobre Juan del Pozo. Este, padrino de María, que recibió las aguas de bautismo el miércoles 8 de enero de 1603 de manos de Gonzalo Jiménez, era un mercader francés y vecino de la collación de Santa María la Mayor (la Catedral), concretamente de la "calle de Francos" $"$. Esta calle había sido ocupada en principio por extranjeros, de los cuales un gran número eran franceses, que disfrutaban de ciertos privilegios fiscales, aunque desde el siglo XIV había venido siendo habitada por vecinos de la ciudad.

En lo que respecta a los meses en los que se bautizó a un número mayor de expósitos, en el período completo, es decir, entre 1597 y 1611, fue abril, con una media de 7,7 niños ${ }^{96}$. En el período comprendido entre 1597 y 1603, coincide en que este fue el mes con el mayor número de expósitos que recibieron las aguas del bautismo con una media de 5,497. Sin embargo, en el segundo, entre los años 1604 y 1611, fue el mes de febrero con una media de 3,398. Aquí, observamos cómo la diferencia de expósitos en ambos períodos fue de 2,1 niños en el mes con mayor número de bautismos, lo que significa un descenso considerable con respecto del período anterior.

En cuanto a los meses con un menor número de bautismos, destaca que en el primer período fue septiembre, con una media de 2,1 niños ${ }^{99}$. En el segundo período, nos encontramos con que el mes con menos niños registrados fue diciembre con una media de $0,9^{100}$. Aquí, podemos observar también ese descenso de expósitos en el segundo período, que es el mayor de ambas etapas ${ }^{101}$. En las dos gráficas que se presentan a continuación pueden observarse los datos de los meses con el mayor y menor número de expósitos que recibieron el sacramento de iniciación cristiana. La primera gráfica corresponde a los bautizos desde 1597 hasta 1603 y, la segunda, desde 1604 hasta 1611. Ambas están detalladas por años y meses.

\footnotetext{
Libro 1597-1603, fol. 202r.

Libro 1597-1603, fol. 285.

Libros $1597-1603$ y $1604-1611$.

Libro 1597-1603.

Libro 1604-1611.

Libro 1597-1603.

Libro 1604-1611.

${ }_{101}$ Libros $1597-1603$ y 1604-1611.
} 


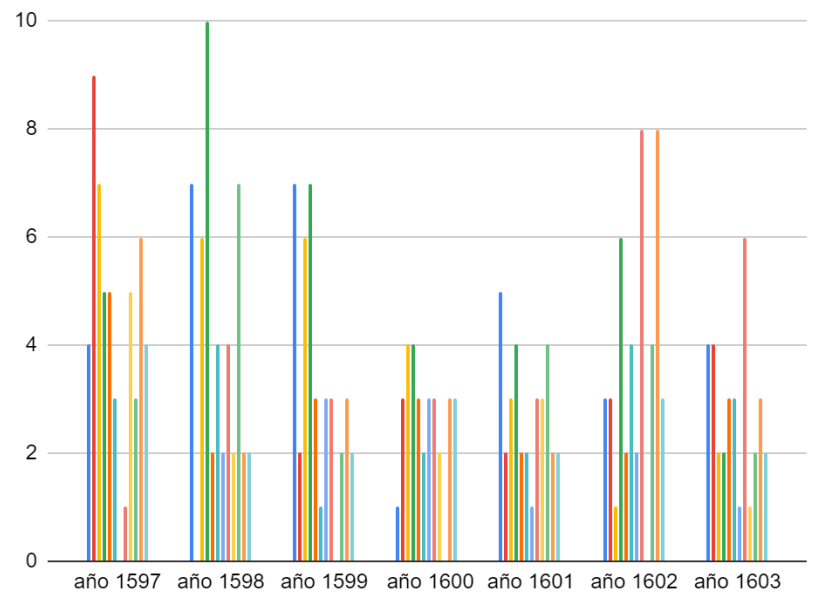

$\square$ enero
febrero
marzo
abril
mayo
junio
julio
agosto
septiembre
octubre
noviembre
diciembre

10

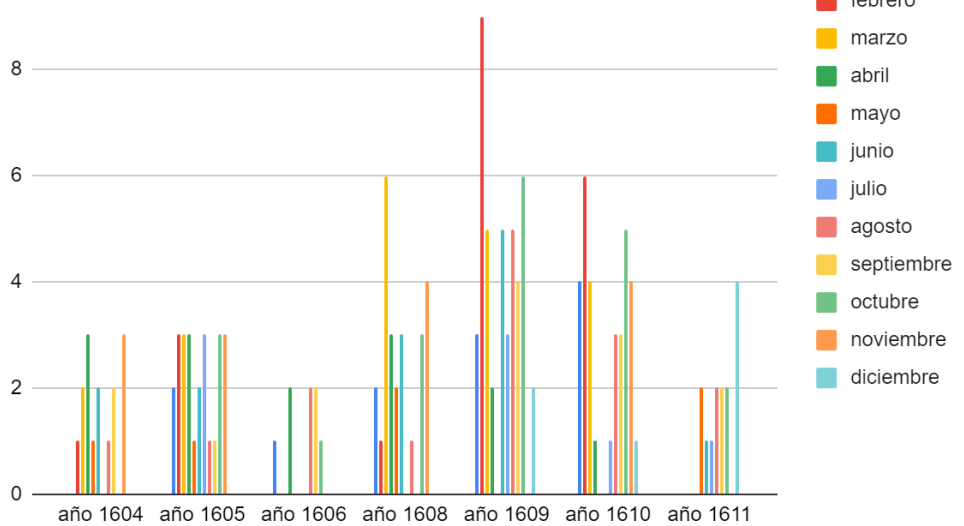

10

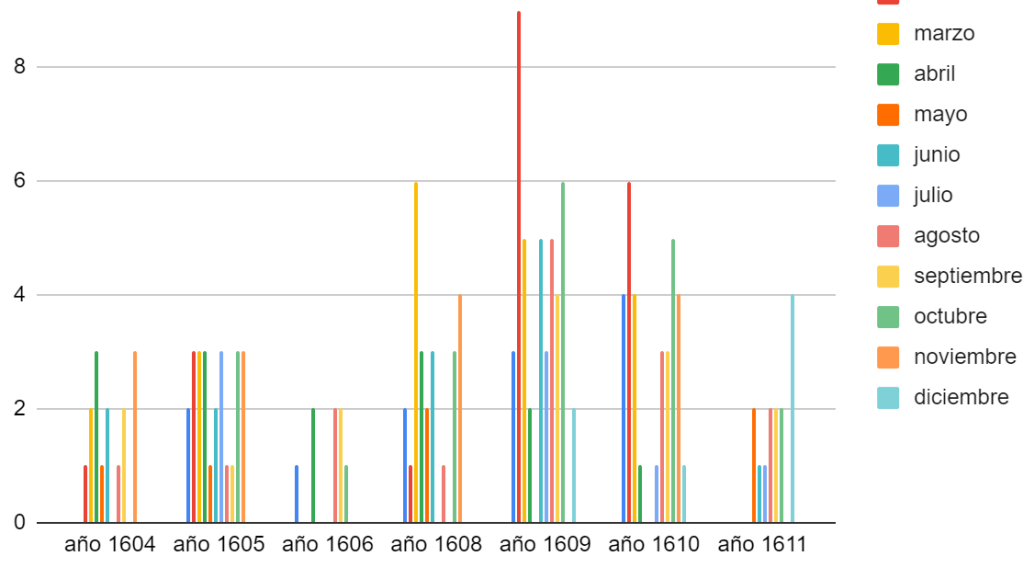




\section{El segundo período (1647-1652)}

A partir de ahora, vamos a analizar el período comprendido entre 1647 y 1652. La importancia de este período deriva del establecimiento de la Casa Cuna y sus avances, sobre todo a nivel organizativo ${ }^{102}$. Su ubicación en la collación de la Magdalena y la constitución de la nueva hermandad que se hizo cargo de ella fueron factores cruciales para el desarrollo de los acontecimientos relacionados con los expósitos. De ahí la importancia de este período. Además, estos años tienen una especial relevancia debido a la peste que asoló la ciudad de Sevilla en $1649^{103}$. Es por ello por lo que el número de expósitos varió mucho de un año para otro, tal y como veremos con los datos obtenidos de los registros bautismales de la Magdalena durante estos años.

Observamos cómo los años 1647 y 1648 fueron en los que más expósitos se bautizaron $^{104}$. En el primero, el total fue de $91^{105} \mathrm{y}$, en el segundo, esta cifra ascendió hasta los $131^{106}$, el pico más alto de los niños expósitos analizados ${ }^{107}$. En este período de 1647 a 1652, fueron bautizados un total de $318^{108}$ expósitos, por lo que el pico ya señalado supuso el $41 \%$ de todos los expósitos de estos seis años. En esta gráfica puede observarse dicha evolución.

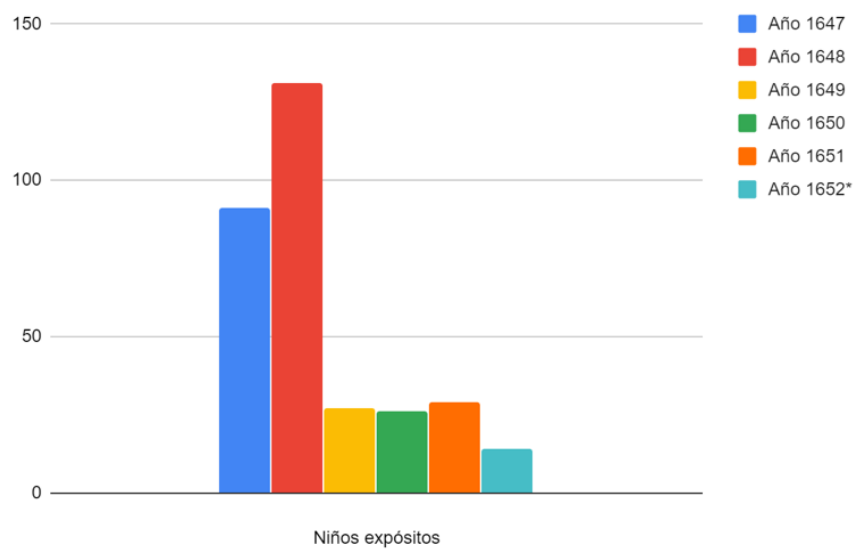

Esa tendencia a la baja se observa claramente en el año 1649. Eso significa que, ya a mediados de 1648 , se dio un número menor de concepciones o que muchos niños pudieron nacer muertos por haberse contagiado sus madres de la peste que ya entonces se extendía por la ciudad, como veremos a continuación. El posible descenso de concepciones pudo deberse a la crisis de subsistencia que se vivió en los años anteriores ${ }^{109}$, lo cual suele tener una repercusión muy clara en la demografía, debido

\footnotetext{
Para su fundación y funcionamiento véase: Álvarez, op. cit. (nota 31), pp. 5-15.

03 Una descripción del impacto de la epidemia en la ciudad está recogida en: Núñez, op. cit. (nota 35), pp. 241-243.

104 Libro 1647-1655, fols. 3r-92v.

105 Ibidem, fols. 3r-44r.

106 Ibidem, fols. $45 \mathrm{v}-91 \mathrm{v}$.

107 Libros 1597-1603, 1604-1611, 1647-1655.

108 Libro 1647-1655, fols. 3r-188r.

109 Contreras Gay, J.: "Penuria, desorden y orden social en la Andalucía del siglo XVII", en Los marginados en el mundo medieval y moderno, Almería, Universidad de Almería, 2000, pp. 214-215.
} 
a que el cereal y la alimentación en general son factores clave para la natalidad y mortalidad de una sociedad. A esto hay que sumarle las consecuencias de la peste que se produjo en 1649, que comenzó en 1648, aunque en ese año aún no estaba descontrolada ${ }^{110}$. Como hemos visto anteriormente, hasta este año el número de bautizos de expósitos fue muy elevado. De hecho, podemos destacar el jueves 16 de abril de 1648, cuando se celebró el bautizo de hasta seis "hijos de la Cuna". Todos ellos fueron bautizados por un mismo sacerdote que les echó las aguas del bautismo y a cada uno de ellos se les amonestó el parentesco espiritual con un padrino diferente ${ }^{111}$.

Pueden observarse más datos a raíz de los registros de bautismo. Es el caso del número de varones y de niñas expósitos que fueron bautizados durante esos años. A este respecto, podemos señalar que son prácticamente idénticos. De hecho, el número total de varones fue de 163 frente al de mujeres, que fueron $155^{112}$. Si hacemos los porcentajes, estos son de un 51\% y un 49\%, respectivamente. También podemos ver cómo los meses en los que más expósitos se bautizaron fueron los comprendidos entre febrero y mayo. De entre ellos, el mes en el que más bautizos se registraron fue mayo, con un total de 40 en seis años. Lo siguen de cerca marzo con 35 y febrero y abril con 33. Por el contrario, los meses en los que menos expósitos se registraron fueron julio y agosto, con 10 y 12 registros respectivamente. De todos modos, se puede seguir la tendencia que se dio en los años anteriores en estos meses para deducir que no sería mucho más alta. Dicha tendencia, sin apenas fluctuaciones, fue de un máximo de 3 expósitos en el mes de julio de $1650^{113}$. La cifra más alta en el mes de junio de este mismo año fue de un total de $4^{114}$. Es por ello por lo que podemos afirmar que el mes con más expósitos bautizados fue mayo y el que menos, julio.

Esta clara tendencia a un número mayor de nacimientos entre los meses de febrero y mayo nos lleva a concluir, teniendo en cuenta el período de gestación más común, que ronda los nueve meses, que gran parte de las concepciones se daban entre los meses de mayo (las de aquellos que nacían en febrero) y agosto (las correspondientes a los niños nacidos en el mes de mayo). Tal y como indicábamos dos párrafos más arriba, la alimentación es fundamental para la supervivencia de las personas. Por eso, coincide la época de un mayor número de concepciones con los meses en los que se recogen las cosechas, lo que propiciaba mejoras en la salud. Estos datos acerca de los bautizos de expósitos registrados por meses y años podemos verlos en la gráfica que se presenta a continuación.

110 Hervás, G.: "Huye luego, lexos y largo tiempo. La pintura de niños de Murillo y la peste de Sevilla de 1649". De Arte: revista de Historia del Arte, 14 (2015), pp. 79-80.

111 Libro 1647-1652, fol. 64r.

112 Libro 1647-1655.

113 Ibidem, fols. 262-264.

114 Ibidem, fols. 265-267. 


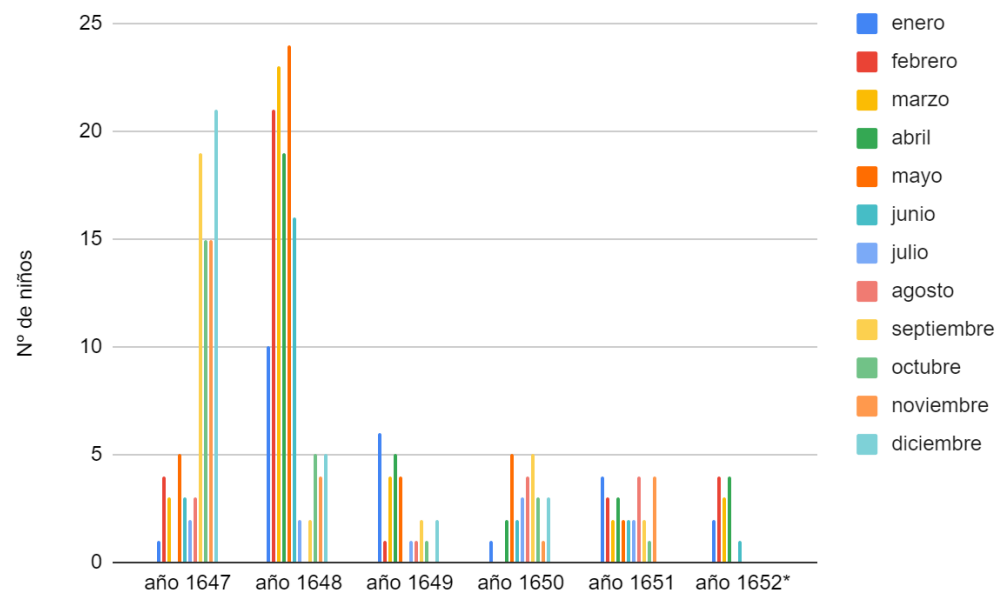

En relación con los padrinos, podemos ver cómo no aparece la collación a la que pertenecían tal y como veíamos a finales del XVI y principios del XVII. Ahora bien, permanece la tendencia de anotar si los padrinos eran clérigos, presbíteros o diáconos ${ }^{115}$. Es el caso del licenciado Bartolomé Cericó, "presbítero capellán de esta iglesia", que fue padrino de Ana, quien recibió las aguas del bautismo el jueves 5 de diciembre de 1647 por el presbítero Juan Vivas Reinoso, con la denominación de "hija de la Cuna"116. Ocurre también más adelante, incluso en 1652, último año del estudio, en el que aparece Tomás de Valdés, de quien se da la información de que era clérigo diácono ${ }^{117}$. Sin embargo, no solo aquellos que pertenecían al clero eran anotados como presbíteros, diáconos y demás órdenes, sino que también se anotaban aquellos que poseían algún cargo dentro de la parroquia. Fue el caso de Gregorio Castellano, "prioste del santísimo Sacramento de esta iglesia"118. Este fue padrino de bautismo de Inés María, "hija de la Iglesia", bautizada por Jerónimo Rol el sábado 9 de marzo de $1647^{119}$. La figura del prioste era el cargo más importante dentro de las cofradías. Era el que se encargaba de la organización de actividades vinculadas al resto de la sociedad y tenía la responsabilidad de llevar a cabo los negocios que tenían las cofradías como es el caso de la venta y arrendamiento de las propiedades de estas ${ }^{120}$.

Observamos cómo muchos de los niños eran bautizados con el nombre de sus padrinos. Es el caso de Pedro Herrero, a quien se le amonestó el parentesco espiritual con Pedro, "hijo de la Iglesia", bautizado por el licenciado Juan de la Barrera el lunes 6 de mayo de $1647^{121}$. Existen más ejemplos. Esta práctica se daba de manera habitual y la vemos especialmente en los niños que son bautizados con nombres compuestos para así llevar el del padrino. Este es el caso de Antonio Félix, cuyo padrino fue Antonio de Figueredo. Este bautizo se celebró el domingo 15 de septiembre

\footnotetext{
115 Ibidem.

116 Ibidem, fol. 39r.

117 Ibidem, fol. 180r.

118 Ibidem., 97-98.

119 Ibidem. Fol. 7r.

120 Pérez González, S.M.: Los laicos en la Sevilla Bajomedieval, Huelva, Universidad de Huelva, 2005, p. 135.

121 Ibidem, fol. $15 \mathrm{r}$.
} 
de $1647^{122}$. Además, destaca también que algunos niños tenían tanto padrino como madrina. Sucedió en el caso de Domingo, con quien Domingo Sánchez y Mariana establecieron el parentesco espiritual por medio del bautismo celebrado el domingo 23 de junio de 1647 por el presbítero Jerónimo Rol ${ }^{123}$.

Se puede observar al analizar las páginas de los libros bautismales cómo existe una constante en relación con los nombres que reciben los niños bautizados, ya sean estos expósitos o no. Sin embargo, como estamos estudiando los expósitos, vamos a hacer un análisis de los nombres más comunes y las posibles razones para que sea repitan un número tan grande de veces en este colectivo. A continuación, se pueden observar dos gráficas que nos indican cuáles son los nombres más comunes entre 1597 y $1611^{124}$ y, más adelante, una segunda gráfica que recoge estos mismos datos de los años $1647-1652^{125}$.

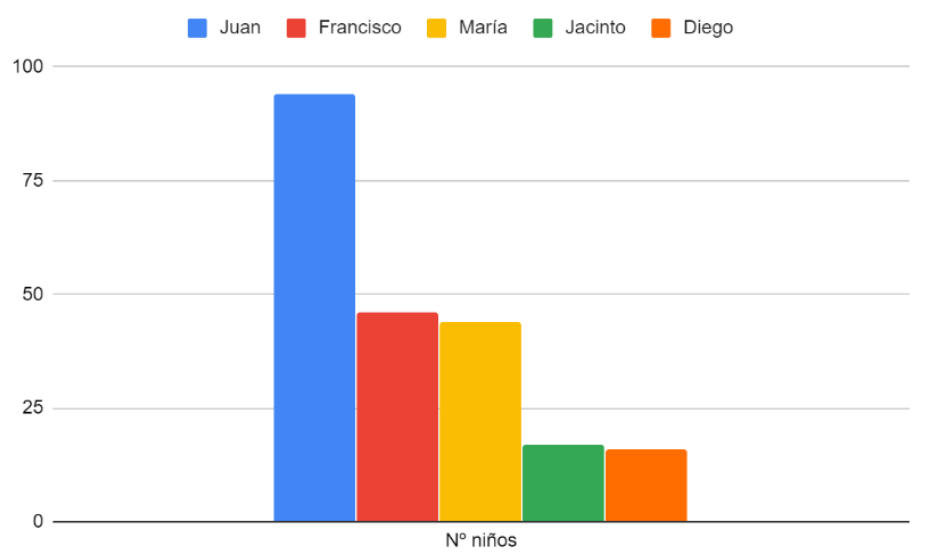

El nombre de Jacinto fue muy común entre los años 1597 y 1611 . De hecho, como podemos observar en la gráfica, se trata de un nombre con el que fueron bautizados un total de 16 expósitos en este período de tiempo ${ }^{126}$. La parroquia de la Magdalena está actualmente en lo que fue el convento de Santo Domingo ${ }^{127}$, por lo que no es de extrañar que muchos niños fueran bautizados con este nombre, ya que san Jacinto fue un dominico que vivió en la época de santo Domingo y al que conoció personalmente. Después de este encuentro, decidió dedicarse a predicar el Evangelio en zonas de la actual Polonia y Ucrania ${ }^{128}$. Su canonización había tenido lugar en 1594, por lo que puede ser que los dominicos estuvieran difundiendo la devoción a uno de los miembros de su Orden recién canonizado ${ }^{129}$.

122 Ibidem, fol. $27 \mathrm{v}$.

123 Ibidem, fol. 20r.

124 Libros 1597-1603, 1604-1611.

125 Libro 1647-1655.

126 Libros 1597-1603 y 1604-1611.

127 Martínez Carretero, I.: "Expolio del patrimonio de órdenes religiosas en Sevilla (1810-1835)", en La desamortización: I expolio del patrimonio artístico y cultural de la Iglesia en España: Actas del Simposium, 6/9-IX-2007, Madrid, R.C.U., p. 151.

128 Del Río Barredo, M. J.: "Fray Domingo de Mendoza, artífice de fiestas religiosas en el Madrid de la Contrarreforma", Chronica Nova, 39 (2013), pp. 62-64.

129 García Bernal, J. J.: "Perpetuo milagro: la memoria prestigiosa y perdurable de la fiesta religiosa barroca (15901630)", Chronica Nova, 39 (2013), p. 98. 
En cuanto al nombre de María, podemos relacionarlo con la devoción a la Virgen, especialmente extendida en esta ciudad. Destaca el hecho de que algunos de los bautizados incluían en su nombre, ya a partir de 1647, el por aquel entonces misterio y ya dogma de fe de la Inmaculada Concepción de la Virgen María ${ }^{130}$. Sevilla proclamó el Voto concepcionista en 1615, por lo que comenzó a extenderse el nombre de Concepción. Así, nos encontramos con los ejemplos de Bernabé José de la Concepción, bautizado el 12 de diciembre de $1650^{131}$, cerca de la fecha en la que se conmemoraba la Inmaculada Concepción. Un ejemplo más de este atributo de la Virgen reflejado en un nombre es el de María de la Concepción, bautizada el 26 de marzo de $1651^{132}$.

También sobresale el nombre de Francisco. San Francisco de Asís, santo fundador de la orden franciscana, tuvo gran devoción en la ciudad de Sevilla, debido a la labor que desarrollaron sus frailes en ella. Además, ligada a los franciscanos, se extendió también la devoción a san Diego de Alcalá, fraile de esta Orden que nació en San Nicolás del Puerto y que falleció en Alcalá de Henares. Fue canonizado en fechas cercanas a los años de estudio de los expósitos, en 1588.

En sintonía con los franciscanos, destacó el nombre de otro miembro de la orden. Se trata de san Antonio de Padua, cuyo nombre aparece en los registros bautismales con mayor frecuencia en el intervalo comprendido entre 1647 y 1652 que en el de 1597 a $1611^{133}$. Además, aparece también entre los más comunes el nombre de "José". Esto podría deberse a que la capilla que existía en la Casa Cuna estaba dedicada a este santo, esposo de la Virgen María ${ }^{134}$. En la gráfica siguiente podemos ver los datos de los nombres más comunes entre 1647 y 1652.

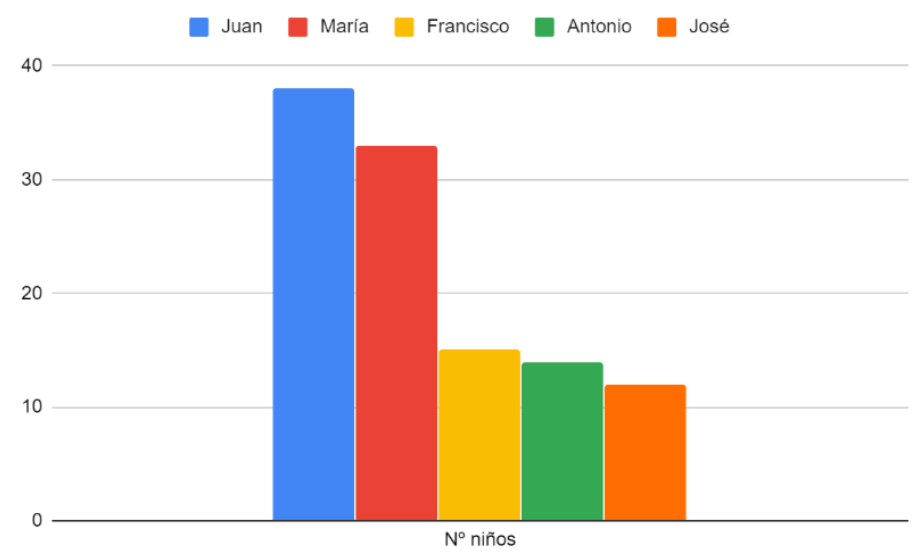

Se puede hablar también de las nuevas devociones de santos canonizados en fechas cercanas, como veíamos con san Laureano y san Diego de Alcalá. En este caso, se trata de santa Teresa de Jesús, canonizada en $1622^{135}$. Así podemos evidenciarlo con

130 Sanz, M. J. "El problema de la Inmaculada Concepción en la segunda mitad del siglo XVII. Festejos y máscaras: el papel de los plateros", Laboratorio de Arte, 8 (1995), pp. 73, 74 y 90.

131 Libro $1647-1655$, fol. $144 \mathrm{v}$.

132 Ibidem, fol. 315 r.

133 Libros $1597-1603$ y $1604-1611$.

134 García Luque, M.: "La capilla de San José de la Casa Cuna de Sevilla: un espacio desaparecido del barroco hispalense", Archivo hispalense: revista histórica, literaria y artística, 300-302 (2016), pp. 391-393.

135 Llamas Martínez, E.: "Santa Teresa de Jesús, gloria de España y Doctora de la Iglesia", Salmanticensis, 3 
el bautizo de Teresa de Jesús, el domingo 20 de octubre de $1647^{136}$. Además, hay que añadir que la práctica de poner el nombre del santo del día estaba bastante extendida. Es el caso, por ejemplo, de Josefa, nacida el 18 de marzo de 1648, un día antes de la festividad de san José137. También podemos observar el caso de Melchora, bautizada el 14 de enero de $1648^{138}$, fecha cercana a la Epifanía del Señor, en la que se celebra tradicionalmente la visita de los Reyes Magos. Observamos también a Blas, quien recibió las aguas del bautismo el viernes 11 de febrero de $1611^{139}$, justo el día de la festividad de san Blas. Y el caso de Roque, bautizado el 12 de agosto de 1601, días antes de la celebración de este santo que, además, era y es el santo protector contra las epidemias y las pestes. Su festividad se celebraba ya por aquel entonces el 16 de agosto $^{140}$, por lo que se seguía en muchas ocasiones el santoral.

\section{Consideraciones finales}

A lo largo de estas páginas hemos podido profundizar en la situación económica, social, histórica y religiosa de la ciudad de Sevilla en los siglos XVI y XVII a partir del análisis de los registros de bautismos de expósitos. Hemos de destacar la evidente influencia del Descubrimiento de América que hizo de la ciudad del Betis un crisol de cultura y de culturas. El trasiego continuo de aquellos que iban y venían en los viajes al Nuevo Mundo repercutió en el desarrollo de esta urbe, con mercaderes de distintas partes del mundo y con el tráfico de productos, ideas y saberes que fueron desarrollándose para servir a las nuevas necesidades.

Una población al alza con más necesidades llevó a una situación de colapso de la ciudad desde el punto de vista del saneamiento y salubridad de las calles, ya deficientes en épocas anteriores, pero que no mejoraban y que derivaban en situaciones poco favorables para la población. Esta situación era el caldo de cultivo perfecto para la proliferación de enfermedades. El trasiego de personas desde muchos y distintos puntos del mundo, junto con estas condiciones en las que se encontraba la mayor parte de collaciones de la ciudad, propiciaron el contagio de algunas enfermedades. Algunas se convirtieron en epidemias e hicieron que la población, que había experimentado un importante incremento desde mediados del siglo XVI, se viera mermada en algunas ocasiones, como son el caso de la peste sufrida a finales del siglo XVI y la que se desarrolló más tarde, la de 1649. No obstante, fue esta última la gran peste que sufrió la ciudad durante los dos siglos que comprende esta investigación.

Nuestro estudio en relación con la situación de los expósitos sevillanos y la respuesta de la Iglesia y la religiosidad a este fenómeno nos permite confirmar que las situaciones de necesidad y de enfermedad, en una sociedad que colocaba a Dios en el centro de todas las cosas, no hacían sino aumentar la fe y la devoción popular. En ello el Concilio tridentino tuvo una repercusión definitiva. Uno de los motivos que

(1967), pp. 641-643.

136 Libro 1647-1652, fol. 32v.

137 Ibidem, fol. 59r.

138 Ibidem, fol. $47 \mathrm{v}$.

139 Ibidem, fol. 398r.

140 Fernández Basurte, Federico: "Epidemias y manifestaciones religiosas en la Málaga del siglo XVII. La Virgen de la Victoria", Baetica. Estudios de Arte, Geografia e Historia, 16 (1994), pp. 311-314. 
llevaban a la exposición de estos niños era la dificultad económica para hacerse cargo de un hijo. Hacia esta dirección apuntan distintos autores, tal y como hemos visto a lo largo del trabajo, ya que tener un hijo o un hijo más en una sociedad con un amplio número de hijos suponía un cambio muy duro para la situación de estas familias. Otro de los motivos es el de la ilegitimidad de los niños concebidos en una relación extramatrimonial. Esta situación pudo deberse a un mayor control sobre los matrimonios y la legitimidad de los mismos. Una mayor observancia del cumplimiento de los mandamientos y la administración de los sacramentos, ejercidos con rigurosidad por supuesto ya con anterioridad, pero que se vieron reforzados por parte de las constituciones tridentinas, pudo suponer un motivo añadido para la exposición.

Sin embargo, esta religiosidad era también la que se encargaba de ejercer la caridad en una sociedad tan necesitada, caridad que con Trento encontró definida la manera en que se debía proceder para ejercitarla. La actividad asistencial que llevaron a cabo las organizaciones eclesiásticas, ya fueran estas formadas exclusivamente por clérigos o con la colaboración de los laicos, fueron clave en el desarrollo de las labores asistenciales. Hemos de destacar una organización eclesiástica relacionada directamente con los expósitos: la Hermandad y Cofradía de Nuestra Señora del Amparo, que se fundó en la parroquia de la Magdalena de Sevilla, fruto de una iniciativa del Cabildo catedralicio y también con su apoyo económico. Desde la Iglesia, tal y como podemos ver en los registros bautismales estudiados, se acogió a estos niños con el mismo trato y dignidad que al resto de neófitos que sí tenían padres reconocidos. Su cuidado espiritual se cubría con la celebración del sacramento del bautismo, por el cual se iniciaban al cristianismo y, tras ser limpiados de pecado original, tenían la oportunidad de disfrutar del cielo prometido a los justos. El bautismo era el primer sacramento y toda la Iglesia, fieles y clero, supo de la necesidad de este incluso para aquellos que habían sido abandonados. Por lo tanto, el hecho de que fueran abandonados no hizo que fueran rechazados, sino todo lo contrario. No obstante, no solo se cubrieron las necesidades espirituales de estos niños. La fundación de una cofradía dedicada exclusivamente al cuidado de las necesidades de los expósitos y el mantenimiento económico de su actividad asistencial no respondía solo a lo espiritual. Se les atendía también en lo material, cuidándolos desde este momento en lugares destinados a ellos y su alojamiento. Se pone así de manifiesto cómo la beneficencia desarrollada por una sociedad es resultado de su propia estructura y de las relaciones de poder entre los distintos colectivos que la conformaban.

Por otro lado, queremos subrayar la importancia de los libros de bautismo como una fuente de información muy valiosa y de primera mano, sin alteración en su contenido, transparente y nítido acerca de lo que ocurrió en la parroquia de la Magdalena durante cincuenta años. El análisis de los registros de bautismo, concretamente las partidas correspondientes a expósitos, supone una fuente primaria de información cuyo valor documental, social e histórico queda fuera de toda duda, arrojando luz sobre hechos que van más allá, como hemos visto, de la administración de este sacramento. Se trata de una información relativa a los padrinos, las collaciones vecinas e, incluso, acerca de las parteras. Estas debían recibir la formación necesaria para poder administrar las aguas de socorro en caso de peligro de muerte del neonato. Aparecen anotaciones en las que se incluye que fueron ellas o las propias madres las que administraron dichas aguas y que fueron ratificadas por el clérigo encargado de acristianar. Se recogen también sucesos ocurridos en la ciudad, como es el caso de un levantamiento del pueblo en el año 1652. También el comienzo de las consecuencias 
de la peste de 1649. Estos son datos de anotaciones directas y concretas. Sin embargo, se pueden deducir otros como los meses con un mayor número de concepciones, así como la influencia del clima y de las cosechas en estas. Hay que sumar también la labor que desarrollaron algunos personajes ilustres en relación con los expósitos, como es el caso del padrinazgo de Ignacio Martínez Montañés, hijo del gran escultor Juan Martínez Montañés.

Por tanto, nos encontramos ante una realidad susceptible de distintos tipos de análisis, pues por un lado se trata de un fenómeno de carácter demográfico, sometido a los ritmos naturales de la población en relación a la natalidad y la mortalidad. Al mismo tiempo el abandono de niños constituye un indudable ejemplo de marginación social, pues los expósitos eran abandonados perdiendo la protección de sus padres, para pasar a ser marcados con distintos estigmas que los convertía en objeto de discriminación por parte de la sociedad a la que pertenecían. En este sentido, el presente trabajo quiere ser una aportación al panorama de la beneficencia española en relación con los niños abandonados durante la Modernidad, panorama que, pese a que aún manifiesta ciertos desequilibrios, se ha visto enormemente enriquecido con nuevos estudios abordados desde perspectivas multidisciplinares. En nuestro caso la seriación de datos que ofrecen los libros de bautismo nos ha permitido introducirnos en cuestiones sociológicas, institucionales y relativas a las mentalidades sociales. En próximos trabajos abordaremos el análisis del resto de las partidas conservadas para proceder, a nivel local, a la comparación con los resultados obtenidos sobre la Casa cuna $\mathrm{y}$, posteriormente, trascender a los niveles nacional e internacional aplicando un método comparativo con otras grandes urbes españolas y europeas sobre estos niños cuya necesidad es entre todas las temporales la más digna de ser socorrida ${ }^{141}$.

\section{Bibliografía}

Acuña León, M.A. y Chavarría López, D.: "Mestizos, mulatos y zambos en la ciudad de Cartago (siglo XVIII), Revista de Historia, 77 (2018), p. 131-155. DOI: http://dx.doi. org/10.15359/rh.77.5 http://www.revistas.una.ac.cr/historia, [Consulta: 10 de octubre de 2019].

Alfani, G. y Gourdon, V. (eds.): Spiritual Kinship in Europe, 1500- 1900, Hampshire, Palgrave MacMillan, 2012.

Álvarez Santaló, L. C.: "La Casa de expósitos de Sevilla en el siglo XVII", en Cuadernos de Historia del Instituto Jerónimo Zurita, VII (1977), pp. 491-532. https://helvia.uco.es/ xmlui/bitstream/handle/10396/11781/2.pdf?sequence=1\&isAllowed=y. [Consulta: 15 de diciembre de 2019].

- Marginación social y mentalidad en Andalucía Occidental: expósitos en Sevilla (16131910), Sevilla, Consejería de Cultura de la Junta de Andalucía, 1980.

Ariès, P.: L'Enfant et le vie familliale sous l'Ancien Régime, París, Plon, 1960.

Arráez Tolosa, A.: "El paso de la epidemia de la peste atlántica de 1596-1602 por Almansa", Al-Basit, 63 (2018), pp. 175-214. https://dialnet.unirioja.es/ejemplar/520682. [Consulta: 25 de abril de 2019].

141 Novísima recopilación de las leyes de España, dividida en XII Libros (...) mandada formar por el Sr. D. Carlos $I V$, t. VII, Madrid, 1805-1807, p. 693. https://bvpb.mcu.es/es/consulta/registro.do?id=403945. [Consulta: 2 de enero de 2020]. 
Baquero, A.: Bosquejo histórico del Hospital Real y General de Nuestra Señora de Gracia de Zaragoza, Zaragoza, Institución "Fernando el Católico", 1952.

Bartolomé Martínez, B.: "La crianza de los expósitos en España entre la Ilustración y el Romanticismo (1790-1835)", Historia de la Educación, 10 (1991), pp. 33-62. http://campus. usal.es/ revistas_trabajo/index.php/0212-0267/article/viewFile/6912/6893. [Consulta: 2 de febrero de 2019].

Benítez Blanco, V.: "Iconografía del purgatorio en las iglesias y conventos de Madrid". El mundo de los difuntos: culto, cofradías y tradiciones, vol. 1, Madrid, Ediciones Escurialenses, 2014. https://dialnet.unirioja.es/servlet/articulo?codigo=5043984. [Consulta: 15 de febrero de 2020].

Bernales Ballesteros, J.: "El urbanismo sevillano de los siglos XVI-XVII", en Historia del urbanismo sevillano, Sevilla, C. S. I. C., 1972., pp. 71-106.

Calvo Ruiz, M.: “Análisis de una defunción en los siglos XVII-XVIII a través de las anotaciones contables que realizaban el colector parroquial", Tiempos Modernos, 15 (2007), pp. 1-14. http://www.tiemposmodernos.org/tm3/index.php/tm/article/view/86/119. [Consulta: 15 de octubre de 2019].

Carmona García, J. I.: "La quiebra de las instituciones benéficas como reflejo de la crisis económica del siglo XVIII”, Archivo Hispalense, 195 (1981), pp. 155-176. https://dialnet. unirioja.es/servlet/articulo?codigo $=3201170$. [Consulta: 15 de mayo de 2020].

Carreras Pachón, A.: El problema del niño expósito en la España ilustrada, Salamanca, Universidad, 1977.

Cartaya Baños, J.: Mayorazgo., Riqueza, nobleza, y posteridad en la Sevilla del siglo XVII, Sevilla, Universidad de Sevilla, España, 2018. https://www.academia.edu/35769627/ MAYORAZGOS_Riqueza_nobleza_y_posteridad_en_la_Sevilla_del_siglo_XVI. [Consulta: 3 de febrero de 2019].

Carvalho, J. y Ribeiro, A. I.: "Using network analysis on parish registers: How spiritual kinship uncovers social structure", en Bridging the Gaps: Sources, Methodology and approaches to Religion in Europe, Edizioni Plus, Pisa, 2008, pp. 171-186. DOI: 10.5007/1518-2924.2014v19n40p157. [Consulta: 3 de abril de 2020].

Castro Pérez, C.: "Las capellanías en los siglos XVII-XVIII a. través del estudio de su escritura de fundación", Anuario de Historia de la Iglesia, 16 (2007), pp. 335-347. https:// dialnet.unirioja.es/servlet/articulo?codigo=2293141, [Consulta: 20 de enero de 2020].

Censo de población de las provincias y partidos de la Corona de Castilla en el siglo XVI, Madrid, Imprenta Real, 1829. https://bibliotecadigital.jcyl.es/es/consulta/registro.cmd?id=7823 [Consulta: 23 de septiembre de 2019].

Constituciones del Arzobispado de Sevilla, Hechas y Ordenadas por el Ilustrísimo y Reverendísimo Señor Don Fernando Niño de Guevara, Cardenal y Arzobispo de Sevilla, en el Sínodo que celebraron en su Catedral el año de 1604. Sevilla, 1609, por Alonso Rodríguez Gamarra. http://hdl.handle.net/10481/23419. [Consulta: 9 de diciembre de 2019].

Contreras Gay, J.: "Penuria, desorden y orden social en la Andalucía del siglo XVII", en Los marginados en el mundo medieval y moderno, Almería, Universidad de Almería, 2000, pp. 211-226. https://dialnet.unirioja.es/servlet/articulo?codigo=2241854, [Consulta: 19 de marzo de 2020].

Coronel Ramos, M. A.: "La caridad: voces de reforma del clero en el siglo XVI", Studia Philologica Valentina, 15 (2013), pp. 182-184. https://www.uv.es/SPhV/15/09_coronel15. pdf. [Consulta: 7 de mayo de 2020].

De la Fuente Galán, M. P. "La creación del Hospicio de Granada", Publicaciones, 25-27 (1996), pp. 141-160. 
Del Pozo y Barajas, A.: Sevilla. Elementos de análisis urbano, Sevilla, Universidad de Sevilla, 2003.

Del Río Barredo, M. J.: "Fray Domingo de Mendoza, artífice de fiestas religiosas en el Madrid de la Contrarreforma", Chronica Nova, 39 (2013), pp. 47-73. http://hdl.handle. net/10481/50738

Demerson, P.: "La Real Inclusa de Madrid a finales del XVIII", Anales del Instituto de Estudios Madrileños, VIII (1972), pp. 261-272. https:/dialnet.unirioja.es/servlet/articulo?codigo $=3011244$. [Consulta: 3 de noviembre de 2019].

Díaz Blanco, J. M.: "La construcción de una institución comercial: el consulado de las naciones flamenca y alemana en la Sevilla moderna", Revista de Historia Moderna Anales de la Universidad de Alicante, 33 (2015), pp. 123-145. https://revistahistoriamoderna.ua.es/ article/view/2015-n33. [Consulta: 9 de marzo de 2019].

Egido, T.: “Aportación al estudio de la demografía española: niños expósitos de Valladolid (siglos XVI-XVIII), en Actas de las I Jornadas de Metodología aplicada de las ciencias históricas, Santiago de Compostela, Universidad, 1975, pp. 333-346.

Eiras Roel, A.: "La Casa de Expósitos del Real Hospital de Santiago en el siglo XVIII", Boletín de la Universidad Compostelana, 75-76 (1967), pp. 295-335.

Esteves Santamaría, M. P.: "Transmisiones de escribanías en Madrid (siglos XVI-XIX)", Cuadernos de Historia de Derecho, 7 (2000), pp. 129-160. https://revistas.ucm.es/index. php/CUHD/article/view/CUHD0000110129A/20257. [Consulta: 20 de mayo de 2019].

Fernández Basurte, F.: "Epidemias y manifestaciones religiosas en la Málaga del siglo XVII. La Virgen de la Victoria", Baetica. Estudios de Arte, Geografía e Historia, 16 (1994), pp. 305-319. https://dialnet.unirioja.es/servlet/articulo?codigo=95306. [Consulta: 25 de marzo de 2020].

Fernández Chaves, M.F. y Pérez García, R.M.: "La penetración económica portuguesa en la Sevilla del siglo XVI", Espacio, Tiempo y Forma, Serie IV, Historia Moderna, 25 (2012), pp. 199-222. http://revistas.uned.es/index.php/ETFIV/article/view/11953 [Consulta: 22 de abril de 2019].

Fernández Ugarte, M.: Expósitos en Salamanca a comienzos del siglo XVIII, Salamanca, Diputación, 1988.

García Bernal, J. J.: "Perpetuo milagro: la memoria prestigiosa y perdurable de la fiesta religiosa barroca (1590-1630)", Chronica Nova, 39 (2013), p. 75-114. https://dialnet.unirioja.es/servlet/articulo?codigo=4636697. [Consulta: 25 de abril de 2020].

García Jiménez, B.: Demografía rural andaluza: Rute en el Antiguo Régimen, Córdoba, Diputación provincial, 1987.

García Luque, M.: "La capilla de San José de la Casa Cuna de Sevilla: un espacio desaparecido del barroco hispalense", Archivo hispalense: revista histórica, literaria y artística, 300-302 (2016), pp. 391-417. https://www.academia.edu/32530938/La_capilla_de_San_ José_de_la_Casa_Cuna_de_Sevilla. [Consulta: 3 de septiembre de 2019].

Girón Pascual, R.M.: "Mercaderes de seda, 'verlegers' y veinticuatros: los Castellano de Marquina de Granada (1569-1644)", en Comercio y cultura en la Edad Moderna Sevilla, Sevilla, Universidad de Sevilla, 2015, pp. 406-410. https://dialnet.unirioja.es/servlet/articulo? codigo $=6004675$ [Consulta: 25 de enero de 2019].

Gómez Martínez, E.: Los niños expósitos en Andújar, Córdoba, Universidad, 1987.

Herrero Sánchez, M. (coord..): Génova y la monarquía hispánica (1528-1713), Génova: Societá Ligure di Storia Patria, 2011.

Hervás, G.: "Huye luego, lexos y largo tiempo. La pintura de niños de Murillo y la peste de Sevilla de 1649", De Arte: revista de Historia del Arte, no 14, 2015, pp. 78-89. https:// 
www.academia.edu/19582191/HUYE_LUEGO_LEXOS_Y_LARGO_TIEMPO_.[Consulta: 7 de abril de 2020].

Irigoyen López, A., Ghirardi, M., Sartori, F.: "Bautismo y padrinazgo en la ciudad de Córdoba (1691-1775)", en Familias históricas, Saõ Leopoldo Oikos-Editora Unisinos, 2015, pp. 19-36. http://revistadeindias.revistas.csic.es/index.php/revistadeindias/oai. [Consulta: 15 de abril de 2020].

Iturralde Valls, M.: "El trabajo infantil en las fábricas indianas, 1736-1800", Revista de Historia industrial, 68 (2017), pp. 13-46. https://dialnet.unirioja.es/servlet/articulo?codigo $=6057437$. [Consulta: 2 de febrero de 2020].

Lacomba Abellán, J. A.: "Las desigualdades interiores en Andalucía en perspectiva histórica. Una aproximación”, Revista de estudios regionales, 54 (1999), pp. 318-319. https:// dialnet.unirioja.es/servlet/articulo?codigo=252518 [Consulta: 23 de noviembre de 2019].

León Vegas, M.: "Un estudio de caso sobre abandono infantil en la Andalucía Moderna: los expósitos de la inclusa antequerana", Revista de Demografía Histórica, n 33, 2015, p. 124. https://dialnet.unirioja.es/servlet/articulo?codigo $=5367773$. [Consulta: 21 de marzo de 2020].

Llamas Martínez, E.: "Santa Teresa de Jesús, gloria de España y Doctora de la Iglesia". Salmanticensis, $\mathrm{n}^{\text {0 }}$ 3, 1967, pp. 641-697. https://dialnet.unirioja.es/servlet/articulo?codigo=1351532. [Consulta: 3 de mayo de 2020].

López Picher, M.: "Los primeros años de la inclusa de La Coruña, bajo el patronato de la venerable Congregación del Divino Espíritu Santo y María Santísima de los Dolores (1739-1799)", en La Iglesia española y las instituciones de caridad, El Escorial, Ediciones Escurialenses, 2006, pp. 579-616. https://dialnet.unirioja.es/servlet/articulo?codigo=2819337. [Consulta: 25 de enero de 2020 ].

López Yepes, J.: Historia de los Montes de Piedad en España, Madrid, Universidad Complutense, 1971. https://dialnet.unirioja.es/servlet/tesis?codigo=270166. [Consulta: 8 de agosto de 2019].

Martín Riego, M.: "Enseñanza y clero parroquial en la Archidiócesis de Sevilla (1750-1800)", Escuela Abierta, 5 (2002), pp. 221-266. https://dialnet.unirioja.es/servlet/articulo?codigo $=286631$. [Consulta: 6 de noviembre de 2019].

Martínez Carretero, I.: "Expolio del patrimonio de órdenes religiosas en Sevilla (18101835)", en La desamortización: I expolio del patrimonio artístico y cultural de la Iglesia en España: Actas del Simposium, Madrid, R.C.U., p. 139-166. https://dialnet.unirioja.es/ servlet/articulo?codigo $=2777343$. [Consulta: 15 de diciembre de 2019].

Martínez Carrión, J.M.: El nivel de vida en la España rural, siglos XVIII-XIX, Alicante, Universidad, 1997.

McCants, A.: Civic charity in a Golden Age. Orphan care in Early Modern Amsterdam, Chicago, University of Illinois Press, 1997.

Menéndez Pidal, R.: "La crisis del siglo XVII. La población, la economía, la sociedad”, en Historia de España. Madrid, Espasa-Calpe, 1996, pp. 99-102.

Morales Padrón, F.: "La historia de Sevilla de Luis Peraza", Boletín de la Real Academia Sevillana de Buenas Letras: Minervae Baeticae, 6 (1978), pp. 75-173. https://dialnet. unirioja.es/ejemplar/283260 [Consulta: 5 de diciembre de 2019].

Novísima recopilación de las leyes de España, dividida en XII Libros (...) mandada formar por el Sr. D. Carlos IV, t. VII, Madrid, 1805-1807, p. 693. https://bvpb.mcu.es/es/consulta/registro.do?id=403945. [Consulta: 25 de enero de 2020].

Núñez, Roldán, F.: La vida cotidiana de la Sevilla del Siglo de Oro, Madrid, Sílex, 2004. 
Pascual Ramos, E.: "Hospicios y expósitos en Mallorca durante el siglo XVIII (1701-1811), en Saitabi, 66 (2016), pp. 101-119. https://doi.org/10.7203/saitabi.66.9635. [Consulta: 4 de octubre de 2019].

Peña Díaz, M: "El Guadalquivir: Sueños y representaciones en el Siglo de Oro", E-Spania. 2015. https://journals.openedition.org/e-spania/24440 [Consulta: 20 de febrero de 2020].

Pérez García, R. M.: "La población del reino de Sevilla en 1571 y las consecuencias demográficas de la guerra de Granada", Archivo Hispalense, 279-281 (2009), pp. 141-162.

- "Mercaderes burgaleses en la Andalucía de los siglos XVI y XVII: Procesos de enriquecimiento, ascenso social y ennoblecimiento", en Monarquías en conflicto. Linajes y noblezas en la articulación de la Monarquía Hispánica, Madrid, Fundación Española de Historia Moderna, 2018, p. 617-627. http://dx.doi.org/10.20350/digitalCSIC/12278 [Consulta: 10 de enero de 2019].

Pérez González, S. M.: Los laicos en la Sevilla Bajomedieval, Huelva, Universidad de Huelva, 2005.

Pérez González, S. M. y Arboleda Goldaracena, J. C.: "Mujeres e Iglesia en Andalucía a finales de la Edad Media", en Actas de la I Jornada de Historia. Conmemoración del 50 Aniversario del fallecimiento de don Hipólito Sancho, Jerez de la Frontera, Centro de Estudios Históricos Jerezanos, 2016, p. 131-154.

Pérez-Mallaína Bueno, P. E.: "Sevilla centro de la Carrera de Indias y de la náutica española en el siglo XVI", en Actas de las II Jornadas de Andalucía y América, v. 1, Sevilla, Universidad de Sevilla, 1983, p. 307.

Pozo Ruiz, A.: "Demografía de Sevilla en el siglo XVI", en De cómo creció la población sevillana. https://personal.us.es/alporu/histsevilla/poblacion.htm [Consulta: 30 de enero de 2020].

Ryckebusch, O.: Les hôpitaux généraux du Nord au siècle des Lumières (1737-1789), Villeneuve d'Ascq, Presses Universitaires du Septentrion, 2017.

Rumeu de Armas, A.: Historia de la previsión social en España. Cofradías, Gremios, Hermandades, Montepíos, Barcelona, El Albir, 1981.

Safley, T. M.: Charity and economy in the orphanages of early modern Augsburg, Boston: Humanities Press, 1997.

Sánchez Herrero, J.: Synodicon Baeticum I I. Constituciones conciliares y sinodales del Arzobispado de Sevilla, t. I: años 1590-1604, Sevilla, Universidad de Sevilla, 2007.

Sanz, M. J.: "El problema de la Inmaculada Concepción en la segunda mitad del siglo XVII", Laboratorio de Arte, 8 (1995), pp. 123-138. http://institucional.us.es/revistas/ arte/08/05\%20sanz.pdf. [Consulta: 4 de abril de 2020].

Schalk, R.: "From orphan to artisan: apprenticeship careers and contract enforcement in The Netherlands before and after the guild abolition", The Economic History Review, 70 (2017), pp. 730-757. https://doi.org/10.1111/ehr.12422. [Consulta: 22 de septiembre de 2019].

Schmidt, A.: "Managing a large household. The gender division of work in orphanages in Dutch towns in the early modern period,1580-1800", History of the Family, 13 (2008), pp. 42-57.

Serrera Contreras, R. M.: "La Casa de la Contratación en el Alcázar de Sevilla (1503-1717)", Boletín de la Real Academia Sevillana de Buenas Letras, 36 (2008), pp. 133-168. https:// dialnet.unirioja.es/servlet/articulo?codigo=3687717 [Consulta: 30 de octubre de 2019].

Tarifa Fernández, A.: "La infancia marginada en la Edad Moderna: los niños expósitos de Úbeda", Andalucía en la Historia, 1 (2003), pp. 62-68.

Terpstra, N.: Abandoned Children of the Italian Renaissance: Orphan Care in Florence and Bologna, Baltimore, Johns Hopkins University Press. 2005. 
Valverde Lamfus, L.: "Los niños guipuzcoanos en la inclusa de Pamplona en el siglo XVIII”, Bilduma, 1 (1987), pp. 109-128. https://dialnet.unirioja.es/servlet/articulo?codigo=7177988. [Consulta: 10 de septiembre de 2019].

Zamora Rodríguez, F.: “Quando el agua llegare aquí Sevilla...”. La avenida del río Gaudalquivir en 1626 según un documento de la Biblioteca de Ajuda (Portugal), Lisboa, Centro de História d'aquém e d'além-mar, 2014.

Zorrilla, E.: Valladolid: sus pobres y la respuesta institucional (1750-1900), Valladolid, Universidad, 1985. 